\title{
Upcycling discarded cellulosic surgical masks into catalytically active freestanding materials
}

\author{
Javier Reguera $\mathbb{C} \cdot$ Fangyuan Zheng $\cdot$ Ahmed Esmail Shalan $\cdot$ Erlantz Lizundia $\mathbb{C}$
}

Received: 25 November 2021 / Accepted: 14 January 2022 / Published online: 1 February 2022

(C) The Author(s) 2022

\begin{abstract}
The COVID-19 pandemic outbreak has resulted in the massive fabrication of disposable surgical masks. As the accumulation of discarded face masks represents a booming threat to the environment, here we propose a solution to reuse and upcycle surgical masks according to one of the cornerstones of the circular economy. Specifically, the non-woven cellulosic layer of the masks is used as an environmentally sustainable and highly porous solid support for the controlled deposition of catalytically active metal-oxide nanoparticles. The native cellulosic fibers
\end{abstract}

Supplementary Information The online version contains supplementary material available at https://doi.org/10.1007/ s10570-022-04441-9.

\author{
J. Reguera $(\bowtie) \cdot$ F. Zheng · A. E. Shalan . \\ E. Lizundia $(\bowtie)$ \\ BCMaterials, Basque Center for Materials, Applications, \\ and Nanostructures, UPV/EHU Science Park, \\ 48940 Leioa, Spain \\ e-mail: javier.reguera@bcmaterials.net \\ E. Lizundia \\ e-mail: erlantz.liizundia@ehu.eus
}

A. E. Shalan

Central Metallurgical Research and Development Institute (CMRDI), P.O. Box 87, Helwan, Cairo, Egypt

E. Lizundia

Life Cycle Thinking Group, Department of Graphic Design and Engineering Projects, Faculty of Engineering in Bilbao, University of the Basque Country (UPV/EHU), 48013 Bilbao, Spain from the surgical masks are decorated by titanium dioxide $\left(\mathrm{TiO}_{2}\right)$, iron oxide $\left(\mathrm{Fe}_{\mathrm{x}} \mathrm{O}_{\mathrm{y}}\right)$, and cobalt oxide $\left(\mathrm{CoO}_{\mathrm{x}}\right)$ nanoparticles following a simple and scalable approach. The abundant surface $-\mathrm{OH}$ groups of cellulose enable the controlled deposition of metaloxide nanoparticles that are photocatalytically active or shown enzyme-mimetic activities. Importantly, the hydrophilic highly porous character of the cellulosic non-woven offers higher accessibility of the pollutant to the catalytically active surfaces and high retention in its interior. As a result, good catalytic activities with long-term stability and reusability are achieved. Additionally, developed free-standing hybrids avoid undesired media contamination effects originating from the release of nanoscale particles. The upcycling of discarded cellulosic materials, such as the ones of masks, into high-added-value catalytic materials, results an efficient approach to lessen the waste's hazards of plastics while enhancing their functionality. Interestingly, this procedure can be extended to the upcycling of other systems (cellulosic or not), opening the path to greener manufacturing approaches of catalytic materials.

Graphical abstract A novel approach to upcycle discarded cellulosic surgical masks is proposed, providing a solution to reduce the undesired accumulation of discarded face masks originating from the COVID-19 pandemic. The non-woven cellulosic layer formed by fibers is used as solid support for the controlled deposition of catalytically active titanium 
dioxide $\left(\mathrm{TiO}_{2}\right)$, iron oxide $\left(\mathrm{Fe}_{\mathrm{x}} \mathrm{O}_{\mathrm{y}}\right)$, and cobalt oxide $\left(\mathrm{CoO}_{\mathrm{x}}\right)$ nanoparticles. Cellulosic porous materials are proven useful for the photocatalytic decomposition of organic dyes, while their peroxidase-like activity opens the door to advanced applications such as electrochemical sensors. The upcycling of cellulose nonwoven fabrics into value-added catalytic materials lessens the waste's hazards of discarded materials while enhancing their functionality. a series of non-woven layers designed to avoid the passage of bacteria and viruses in both directions thanks to their tailored pore-geometry and large specific surface area able to block the viruses (Zhu et al. 2020).

The handling and disposal of the healthcare waste arising from the massive use of face masks have become a big concern, not only to control the spread of

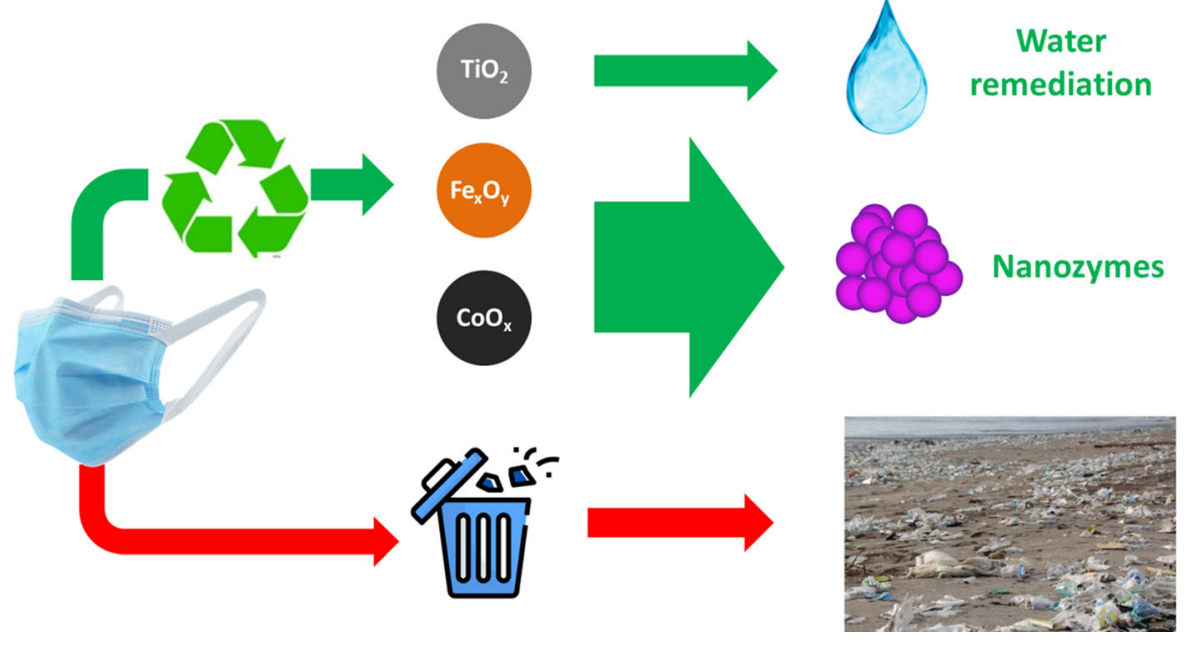

Keywords COVID-19 pandemic - Face masks · Non-woven cellulose · Upcycling · Photocatalysis · Nanozymes · Circular economy

\section{Introduction}

Worldwide demand for surgical face masks has dramatically increased as many governments have made compulsory the use of face masks in public areas due to the COVID-19 pandemic outbreak (Feng et al. 2020). Face masks provide a physical barrier to reduce person-to-person virus transmission, which mostly originates from the respiratory microdroplets subsequent to sneezing and coughing (De Stefano et al. 2020). The face masks composed of polymeric materials have been specially useful to prevent the number of infectious viruses or bacteria in exhaled breath (Armentano et al. 2021). They are composed of the SARS-CoV-2 virus (Thakur 2021), but also to lessen the environmental risks of medical waste when inappropriately disposed of (Wei et al. 2020). Discarded face masks are a booming threat to the planet as they have been encountered in the form of microplastics both in marine and landfill environments (Dharmaraj et al. 2021), reflecting the need to prevent such waste from uncontrolled leaking. In early 2022, 2 years after pandemic's start, the world is witnessing an explosion of new virus cases with the emergence of the Omicron variant (Kupferschmidt and Vogel 2022), leading to an accumulation of unused disposable face masks. Instead of representing a problem, these unused masks offer an opportunity for novel circular economy practices (Corrêa and Corrêa 2021; Selvaranjan et al. 2021). Interestingly, the surgical masks can be easily sterilized by dry heat, microwave radiation of ultraviolet light (UV-C light irradiation for $10 \mathrm{~min}$ from each side effectively kills the coronavirus) (Ben et al. 2021), or with $121{ }^{\circ} \mathrm{C}$ steam 
or $\mathrm{H}_{2} \mathrm{O}_{2}$ plasma (van Straten et al. 2021). As these approaches barely damage the functionality and the structure of the porous layers of the masks, these materials can be safely applied in different fields. Taking reuse and recycling practices into consideration as one of the cornerstones of circular economy (Kirchherr et al. 2017), providing second life to surgical face masks represents a plausible approach to lessen the environmental impacts arising from their undesired accumulation into marine and land environments. The upcycling of discarded materials into high-value functional products have been already proven efficient to reduce the waste's hazards of polymers while enhancing their functionality (Górak et al. 2020; Lauria and Lizundia 2020).

Disposable surgical masks are typically made of three layers of non-woven fabrics (Armentano et al. 2021). The first layer prevents fluids carrier penetration, the second layer retains viruses and the inner third layer absorbs fluids from the user (Wibisono et al. 2020). Although the composition can vary, the filter layer typically consists of a cellulose-based fabric, while the outer layers are made of polypropylene or in many cases of cellulose layers, offering in this last case of a more skin-friendly surface (Bilgi et al. 2021). Provided by its abundant surface hydroxyl $(-\mathrm{OH})$ groups, cellulose offers a recyclable and environmentally sustainable solid support for the controlled deposition of metal/metal-oxide nanoparticles (Mousli et al. 2020; Tang et al. 2020). Importantly, nano-, meso- and micro-porous membranes can be easily achieved with cellulose through diverse fabrication approaches (Lizundia et al. 2020), which makes this renewable material particularly versatile. The three $\mathrm{OH}$ groups at the 2-, 3- and 6-position in the anhydroglucose repeating unit act as concomitant reducing and capping agents for metal/metal-oxide nanoparticle immobilization (Musino et al. 2021). Accordingly, different catalytically active nanoparticles have been deposited onto cellulosic substrates, including zinc oxide (Awan et al. 2018), palladium (Wu et al. 2016), platinum (Lizundia et al. 2019), or gold (Yan et al. 2016). The synergetic effects arising from the cellulosic substrate and the inherent catalytic activity of metal/metal-oxides open novel opportunities for a variety of applications.

In this framework, we focus our attention on water remediation given its pivotal role to support plant and animal life. The growing pressure arising from the world population increase coupled with the extended use of chemicals has resulted in contaminated water reservoirs (Steffen et al. 2015; Ccanccapa et al. 2016). Hence, organic pollutant removal from the water represents a global challenge for the twenty-first century and forms part of the 6th sustainable development goal (SDG) of the United Nations (Karpińska and Kotowska 2019). Photocatalysis results in one of the most promising approaches towards environmental remediation because it enables a platform to trigger diverse chemical reactions which decompose the pollutant into less-active and non-toxic species (Foteinis et al. 2018; Singh and Goldsmith 2020). In a similar fashion, it enables water disinfection through the degradation of pathogens such as bacteria or viruses (Foster et al. 2011; Zhu et al. 2018; RodríguezGonzález et al. 2020). In comparison with other methods such as adsorption (Xia et al. 2020), filtration (Kondo et al. 2020), or reverse osmosis (Liu et al. 2015), photocatalyst particles can be reused with no need for reactivation and can be used under sun illumination to reduce the energetic cost. Originating from the inherent photocatalytic activity of titanium dioxide $\left(\mathrm{TiO}_{2}\right)$ (Khin et al. 2012), the immobilization $\mathrm{TiO}_{2}$ nanoparticles onto a mechanically flexible solid support such as surgical masks enables a self-standing hybrid capable of catalyzing a large range of reactions when excited with external radiation. Additionally, undesired media contamination effects originating from the release of nanoscale particles are avoided. An additional benefit comes from the hydrophilic porous character of the cellulosic non-woven layer offering higher accessibility of the pollutant to the catalytically active surfaces (Marques et al. 2021). Importantly, photocatalytic sterilization is recognized as a sustainable, cheap, and effective disinfection approach for SARS-CoV-2, simplifying their use once discarded (Ghedini et al. 2021).

The application range of organic-inorganic hybrids can be expanded to a great extent replacing $\mathrm{TiO}_{2}$ with nanozymes, nanoscale-systems with intrinsic enzymelike activities (Wang et al. 2018b; Liang and Yan 2019). Since the pioneering work by Scrimin et al. in 2004 (Manea et al. 2004), nanozymes have been attracting increasing attention for many applications including diagnostic medicine, biosensing, or environmental remediation (Meng et al. 2020). These artificial enzyme-like analogs are easy and cheap to manufacture, offer improved catalytic stability and 
remain stable under harsh physicochemical conditions in comparison with natural enzymes such as globular proteins (Jiang et al. 2019). Among the different nanoparticles that mimic the catalytic activity of enzymes such as peroxidase, oxidase, catalase, haloperoxidase, and others (Wei and Wang 2013; Liang and Yan 2019), $\mathrm{Fe}_{3} \mathrm{O}_{4}$ nanoparticles are specially attractive given their intrinsic ability to oxidize organic substances (Chen et al. 2012; Gao et al. 2017; Maharjan et al. 2020). After its discovery, other metal oxides such as $\mathrm{CoO}_{\mathrm{x}}$ have shown similar activity (Mu et al. 2012; Guo et al. 2020), and opened the way to new types of enzyme-like activities.

Here we explore the potential of discarded surgical masks to develop novel heterogeneous catalytic materials. A general strategy for the fabrication of photocatalytically active or enzyme-mimetic active hybrid nanomaterials is shown upon embedding diverse catalytic metal oxide nanoparticles within the porous structure of cellulosic membranes. Wellknown catalytically active materials including $\mathrm{TiO}_{2}$, $\mathrm{Fe}_{\mathrm{x}} \mathrm{O}_{\mathrm{y}}$, and $\mathrm{CoO}_{\mathrm{x}}$ are used as model examples. The versatility of cellulose as a substrate for catalytically active materials results in materials with efficient degradation activities towards contaminants of emerging concern or marked peroxidase-like activities, paving the way for novel environmental cleanup systems, chemical processes, or sensing. Additional applications could arise in biomedicine or as antifouling fabrics and surfaces. In those cases, some concerns regarding biocompatibility (for instance with $\mathrm{Co}$ ) or possible allergic effects may emerge. Remarkably, the upcycling of cellulosic surgical masks represents a step forward to face the massive mask disposal that occurred during the COVID-19 pandemic.

\section{Materials and methods}

Chemicals and materials

Surgical masks (EN14683, Type II) were kindly provided by Medline Industries, Inc., Australia. For the nanoparticle synthesis, cobalt acetate tetrahydrate was purchased at Alfa Aesar; ferric chloride $\left(\mathrm{FeCl}_{3}\right.$, $99 \%)$, ferrous chloride tetrahydrate $\left(\mathrm{FeCl}_{2} \cdot 4 \mathrm{H}_{2} \mathrm{O}\right.$, 98\%), ethanediol, ethanol, 1,2-diaminoethane, hydrochloric acid ( $\mathrm{HCl} 37 \%$ ), Titanium (IV) isopropoxide (97\%), ammonium hydroxide $\left(\mathrm{NH}_{4} \mathrm{OH}\right.$,
25-30\% of ammonia) at Sigma-Aldrich; $\mathrm{NaOH}$ (98.0\%-100.5\%). For the catalysis experiments $\mathrm{H}_{2} \mathrm{O}_{2}$ $(30 \% \mathrm{w} / \mathrm{v})$ was purchased at Panreac; Methylene blue (MB), and 3,3',5,5'-tetramethylbenzidine (TMB), and acetate buffer $(\mathrm{pH}=4.66)$ at Sigma Aldrich.

Nanoparticle synthesis

\section{Synthesis of $\mathrm{TiO}_{2}$ nanoparticles}

To synthesize $\mathrm{TiO}_{2}$ nanoparticles, Milli-Q water $(200 \mathrm{~mL})$ was added slowly into $10 \mathrm{~g}$ of titanium isopropoxide in a $400 \mathrm{~mL}$ beaker to generate the hydrolysis of the alkoxide and precipitation of hydrous titanium oxides. Immediately afterward, $\mathrm{NaOH}$ solution $(1 \mathrm{M})$ was added slowly until $\mathrm{pH}$ reached 8 . The mixed solution was kept thoroughly mixed by continuous stirring at $100{ }^{\circ} \mathrm{C}$ for $1 \mathrm{~h}$. $\mathrm{pH}$ was checked again and readjusted with $\mathrm{NaOH}$ solution (1 M) to 8. Once the reaction was finished, the final solution was kept stirring at room temperature for $1 \mathrm{~h}$. The white precipitate formed in the reaction was filtered and washed several times with deionized water. The last step was to dry the washed precipitate at $80{ }^{\circ} \mathrm{C}$ in an oven overnight and then anneal it at $400{ }^{\circ} \mathrm{C}$ for $3 \mathrm{~h}$. The final product was ground with a pestle and mortar to obtain a fine powder.

Synthesis of $\mathrm{Fe}_{x} \mathrm{O}_{y}$ nanoparticles through coprecipitation $\left(\mathrm{Fe}_{x} \mathrm{O}_{y}\right.$ sample 1$)$

$\mathrm{Fe}_{\mathrm{x}} \mathrm{O}_{\mathrm{y}}$ nanoparticles were prepared using a co-precipitation technique (Darezereshki 2010). $\mathrm{FeCl}_{3}$ and $\mathrm{FeCl}_{2} \cdot 4 \mathrm{H}_{2} \mathrm{O}$ were dissolved in a $2 \mathrm{M} \mathrm{HCl}$ to form an aqueous solution with the concentration of $1 \mathrm{M}$ for $\mathrm{FeCl}_{3}$ and $2 \mathrm{M}$ for $\mathrm{FeCl}_{2} \cdot 4 \mathrm{H}_{2} \mathrm{O}$. After that, the ammonia solution ( $2 \mathrm{M}$ ) was dropped to this solution with vigorous stirring at room temperature for $2 \mathrm{~h}$. The final $\mathrm{pH}$ was 9.5. The brown precipitate was then collected by filtration and rinsed three times with deionized water and ethanol. Finally, the washed precipitate was dried at $70{ }^{\circ} \mathrm{C}$ overnight.

Synthesis of $\mathrm{Fe}_{x} \mathrm{O}_{y}\left(\mathrm{Fe}_{x} \mathrm{O}_{y}\right.$ sample 2) and $\mathrm{CoO}_{x}$ through diol-based synthesis

The precursors of the different metal oxides were prepared with cobalt acetate tetrahydrate $(0.5 \mathrm{M})$ and a mixture of $\mathrm{FeCl}_{3}$ and $\mathrm{FeCl}_{2} \cdot 4 \mathrm{H}_{2} \mathrm{O}$ as sources of 
$\mathrm{CoO}_{\mathrm{x}}$, and $\mathrm{Fe}_{\mathrm{x}} \mathrm{O}_{\mathrm{y}}$, respectively. These different precursors were dissolved in an ethanediol solution containing 1,2-diaminoethane (1 M) stirred for at least 3 days to form a homogeneous precursor solution (Shalan et al. 2016). The solution was used as obtained without any further purification or calcination.

Fabrication of cellulose-nanoparticle hybrid material

The chosen mask did not present any dye nor colorant, and comprised three non-woven cellulose layers (providing a face mask differential pressure of $24.71 \mathrm{~Pa} \cdot \mathrm{cm}^{-2}$ ), with a thicker interior layer and two identical and more porous exterior layers. The cellulose substrate was obtained from the exterior layers of a surgical mask providing two sheets of $15.5 \times 17$ $\mathrm{cm}^{2}$ after removing the mask borders. The cellulose sheet was immersed in the nanoparticle aqueous solution $(50 \mathrm{~mL})$ at a concentration of $1 \mathrm{~g} \cdot \mathrm{L}^{-1}$ and left for $3 \mathrm{~h}$. After the incubation, the mask was rinsed and immersed in $50 \mathrm{~mL}$ of ultrapure water and left with mild shaking for $2 \mathrm{~h}$. The supernatant was measured by UV-Vis and then discarded. The process was repeated several times until no trace of nanoparticles was observed by UV-Vis (4 times).

\section{Characterization}

Attenuated total reflectance Fourier transform infrared spectroscopy (ATR-FTIR) measurements were performed on a Bruker Alpha FT-IR Spectrometer equipped with diamond ATR optics. Samples were dried at $50{ }^{\circ} \mathrm{C}$ overnight before characterization. 64 scans were taken in the range $400-4000 \mathrm{~cm}^{-1}$ with a resolution of $2 \mathrm{~cm}^{-1}$.

Nanoparticles were dispersed in water and dropcasted in a C-coated TEM grid and left to dry. Samples were measured in a JEOL 1400 working at $100 \mathrm{kV}$. Images were analyzed using Image $\mathbf{J}$ software package, and nanoparticle diameters were measured manually with more than 100 nanoparticles per sample.

Room temperature XRD has been conducted in a PANalytical Empyrean powder diffractometer in reflection mode using $\mathrm{Cu}-\mathrm{K} \alpha$ radiation ( $\lambda=1.5418 \AA$ ) operating at $45 \mathrm{kV}$ and $40 \mathrm{~mA}$ to investigate the crystalline structure of synthesized P-dots. Samples were mounted on a zero background silicon sample holder. Data were collected from 5 to $80^{\circ} 2 \theta$ (step size $=0.026^{\circ}$; angular resolution: $0.026^{\circ}$ ) at RT. Grain size was evaluated using Scherrrer's formula, $\tau=k \lambda \beta \cos \theta$ where the shape factor $k$ was taken as 0.9 , and $\beta$ was obtained from the most intense peak after subtracting the instrumental FWHM of 0.1. The relative composition of the crystalline phases was obtained from the relative areas using a weighted average mass (Cano-Casanova et al. 2018). $W_{A}=K_{A \text { - }}$ $I_{A} /\left(K_{A} I_{A}+K_{B} I_{B}+I_{R}\right), \quad W_{B}=K_{B} I_{B} /\left(K_{A} I_{A}+K_{B} I_{B-}\right.$ $\left.+I_{R}\right)$, and $W_{R}=I_{R} /\left(K_{A} I_{A}+K_{B} I_{B}+I_{R}\right)$, where $W_{A}$, $W_{B}$, and $W_{R}$ are the weight fractions of anatase, brookite, and rutile respective, $I_{A \cdot B}$, or $R$ denotes the integral area and $K_{A}=0.886$ and $K_{B}=2.721$ the correction coefficients.

Mechanical properties of the cellulose membranes were analyzed in uniaxial tensile testing mode on an AGS-X universal testing machine from Shimadzu equipped with a $500 \mathrm{~N}$ load cell in displacement control mode at a rate of $1 \mathrm{~mm} \cdot \mathrm{min}^{-1}$. Rectangleshaped $70 \pm 5 \mu \mathrm{m}$ thick, $20 \mathrm{~mm}$ long, and $12 \mathrm{~mm}$ wide films were used.

For inductively coupled plasma (ICP) studies, the substrate was cut with a $1 \times 1 \mathrm{~cm}^{2}$ was introduced at the bottom of a $15 \mathrm{~mL}$ falcon tube, $\mathrm{HCl}$ and $\mathrm{HNO}_{3}$ (trace analysis purity) were added at a ratio of $3: 1$ to generate aqua regia in situ and left for $1 \mathrm{~h} .5 \mathrm{~mL}$ of Milli-Q $\mathrm{H}_{2} \mathrm{O}$ was added and mixed and the solution was transferred to a new tube. This was repeated with another $5 \mathrm{~mL}$ of $\mathrm{H}_{2} \mathrm{O}$, the sample was centrifuged and the supernatant was taken together with the previous solution to form a $10 \mathrm{~mL}$ solution to be analyzed by ICP. The samples were measured in a quadrupole mass spectrometer with an ICP source (Q-ICP-MS), model XSeries-II (Thermo). An internal standard was introduced by adding $100 \mu \mathrm{L}$ of Yttrium at $500 \mathrm{ppb}$. The measured selected isotopes to perform the quantification were ${ }^{59} \mathrm{Co},{ }^{57} \mathrm{Fe}$, and ${ }^{197} \mathrm{Au}$. The results showed a concentration of nanoparticles of 26.6, 90.5, 30.9, and $3.4 \mu \mathrm{g} \cdot \mathrm{cm}^{2}$ for $\mathrm{TiO}_{2}, \mathrm{Fe}_{\mathrm{x}} \mathrm{O}_{\mathrm{y}}$ samples 1 and 2, and $\mathrm{CoO}_{\mathrm{x}}$ respectively, which corresponds to $1.4,4.2,1.6$, and 0.17 wt. \% respectively (in terms of the metal atoms to the total substrate).

For XPS experiments, a drop of nanoparticle solution was deposited in the XPS holder and left to dry without further preparation. XPS measurements were performed in the SPECS instrument (Berlin, Germany) equipped with an analyzer Phoibos150 1DDLD and monochromatic radiation source $\mathrm{Al} \mathrm{K \alpha}$ $(1486.7 \mathrm{eV})$. A first quick wide scan was carried out to 
determine the present elements (step energy $1 \mathrm{eV}$, dwell time $0.1 \mathrm{~s}$, pass energy $80 \mathrm{eV}$ ) and then a detailed analysis was performed for the different elements (step energy $0.08 \mathrm{eV}$, dwell time $0.1 \mathrm{~s}$, pass energy $30 \mathrm{eV}$ ) with an electron outgoing angle of $90^{\circ}$. The spectrometer was previously calibrated with $\mathrm{Ag}$ (Ag 3d5/2, 368.26 eV). The spectra were fit with the software CasaXPS 2.3.16, which models the GaussLorentzian contributions after background subtraction (Shirley). Concentrations were calculated correcting the values with the relative atomic sensitivity factors (Scofield).

$\mathrm{TiO}_{2}$ nanoparticles were analyzed in a UV-Vis reflectance spectrometer (DRS), using a UV-VisibleNIR Jasco V-770 spectrometer equipped with a $150 \mathrm{~mm}$ diameter integrating sphere coated with Spectralon with $1 \mathrm{~nm}$ spectral resolution. DRS was carried out in the 250-2200 nm wavelength range. A Spectralon reference was used to measure the $100 \%$ reflectance and internal attenuators were used to determine zero reflectance in order to remove background and noise. The powders were placed on a white substrate, sealed, and mounted on a Teflon sample holder for the DRS measurement. The measured reflectance spectra were subsequently converted to Kubelka-Munk (K-M) absorption factors to evaluate the absorption spectra of the powders. The band-gap was estimated via the Tauc plot $[F(R) h v]^{\mathrm{n}} v s . h v$ where $\mathrm{F}(\mathrm{R})$ is the absorbance, $h$ is the Planck constant, $v$ is the frequency, and $\mathrm{n}$ is the sample transition taken as $n=1 / 2$ ) (Granqvist 1995; Sakthivel et al. 2006).

\section{Photocatalysis assays}

A disk shape of the $\mathrm{TiO}_{2}$-containing substrate $(\varnothing=4 \mathrm{~cm})$ was placed at the bottom of a beaker $(100 \mathrm{~mL})$, and then filled with $30 \mathrm{~mL}$ of methylene blue and left under mild orbital shaking. UV-Vis measurements were performed at different times to follow the absorption of the dye by the substrate. The photocatalytic reaction was produced by illumination the substrate from the bottom with a $10 \mathrm{~W}$ and $365 \mathrm{~nm}$ LED that produced $0.6 \mathrm{~W}$ optical power. The solution was maintained under mild shaking and samples were measured at different time intervals. UV-Vis spectra were acquired in a spectrometer (AvaSpec, Avantes) between 200 and $1100 \mathrm{~nm}$. $1 \mathrm{~mL}$ of the solution was taken from the solution in a $1 \mathrm{~cm}$ optical path cuvette, was measured, and added again to the solution (the whole process took less than $30 \mathrm{~s}$ ). The acquired spectra were analyzed using Spectragryph software package.

For the sake of comparison, the apparent reaction rate constant $\left(k_{\text {app }}, \mathrm{min}^{-1}\right)$ was calculated using a firstorder kinetic following the Langmuir-Hinshelwood model according to the equation:

$\ln \frac{C}{C_{0}}=-k_{a p p} \cdot t$

where $C_{O}$ represents the initial $\mathrm{MB}$ concentration (before catalyst incorporation into the polluted media) and $C$ is the apparent concentration at time $t$.

Peroxidase-like catalysis

A solution of 3',5,5' - tetramethylbenzidine (TMB) was prepared first dissolving the TMB in DMSO at a concentration of $1 \mathrm{mg} \cdot \mathrm{mL}^{-1}$ and then diluting it in an acetate buffer ( $\mathrm{pH}=4.66)$ to obtain a final concentration of $0.1 \mathrm{mg} \cdot \mathrm{mL}^{-1}$. The catalytic reaction was performed in a $4 \mathrm{~mL}$ glass cuvette. A piece of the substrate of $4.2 \mathrm{~cm}^{2}$ was weighed and added to the cuvette, then $3 \mathrm{~mL}$ of TMB solution was added and finally, $7.87 \mu \mathrm{L}$ of $\mathrm{H}_{2} \mathrm{O}_{2}$ (30\% vol.) was added to initiate the reaction. The reaction was followed in UV-Vis taking spectra at different time intervals. The reaction progress was monitored by representing the absorbance at $654 \mathrm{~nm}$ as a function of time. A kinetic analysis was performed using the degradation of $\mathrm{H}_{2} \mathrm{O}_{2}$ due to the oxidation of the substrate TMB, and fitting it to a first-order kinetic model. 
A

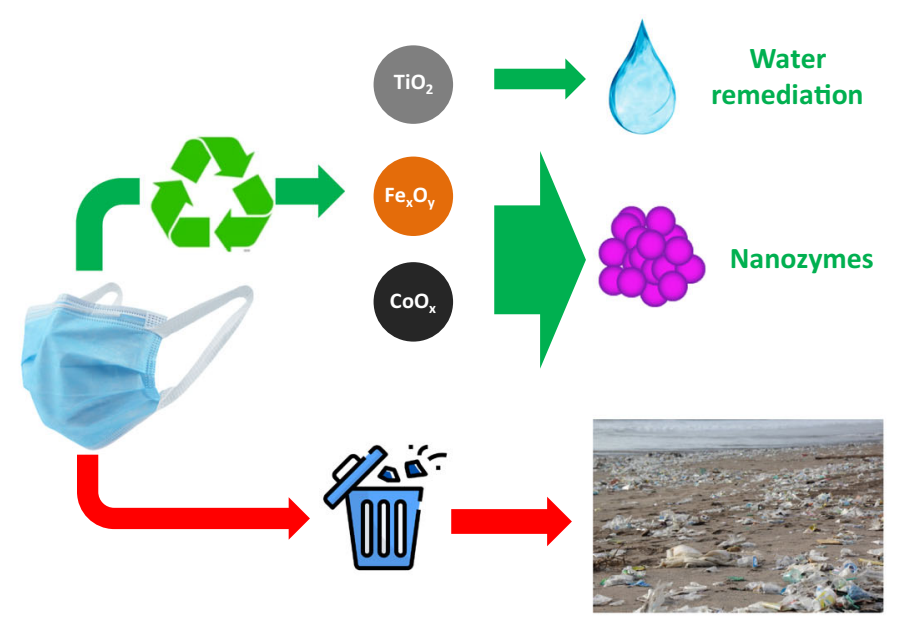

B

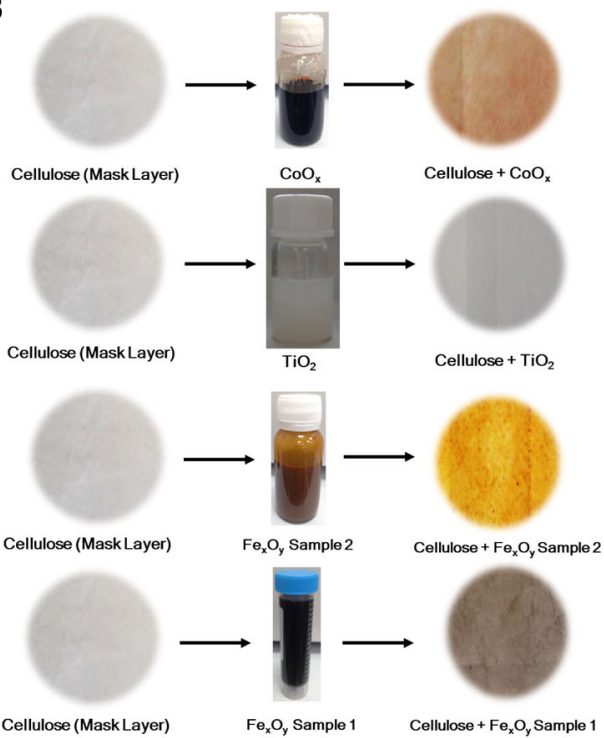

Scheme 1 A Use of cellulosic surgical masks as a platform material to develop catalytic materials upon the incorporation of $\mathrm{TiO}_{2}$ nanoparticles and $\mathrm{Fe}_{\mathrm{x}} \mathrm{O}_{\mathrm{y}} / \mathrm{CoO}_{\mathrm{x}}$ nanozymes. This procedure avoids the uncontrolled disposal of surgical masks.

\section{Results and discussion}

Scope of the work

As summarized in Scheme 1A, here we aim to use the cellulosic layer within the surgical masks as a platform for the development of free-standing catalytically active materials. This approach faces some of the recognized limitations of inorganic nanoparticles when used for catalytic applications. When dispersed in a liquid media nanoparticles tend to aggregate and precipitate as a result of their high surface energy and surface change during the catalysis, thus the available active area to undergo reactions decreases dramatically (Grzelczak et al. 2010). Another equally relevant problem is the difficulty in removing dispersed catalysts from the reaction liquid which leads to undesired medium contamination. Finally, as dispersed nanoparticles are difficult to handle, their reuse is often compromised (Miceli et al. 2021). On the other hand, the cellulose substrates such as the ones found in masks can be reused into a high added value application, avoiding their uncontrolled disposal into marine or land environments (as floating marine debris, masks seriously impact the marine ecosystems) (Chowdhury et al. 2021). To explore the potential of surgical masks
B Scheme with the preparation of catalytic substrates onto cellulose non-woven layers showing the macroscopic appearance of the masks before and after incubation with nanoparticle solutions (stored in the vial)

as three-dimensional substrates for catalytic applications, we turn our attention to $\mathrm{TiO}_{2}$ nanoparticles and $\mathrm{Fe}_{\mathrm{x}} \mathrm{O}_{\mathrm{y}}$ and $\mathrm{CoO}_{\mathrm{x}}$ nanozymes to exploit their inherent water purification and peroxidase-like activity, respectively (Scheme 1B shows the macroscopic visual appearance of the masks before and after nanoparticle loading).

Active material formation and substrate properties

Several types of nanoparticles were synthesized as the active material to modify the mask substrates. This includes $\mathrm{TiO}_{2}$ as photocatalytic nanoparticles, two iron oxide $\left(\mathrm{Fe}_{\mathrm{x}} \mathrm{O}_{\mathrm{y}}\right)$ nanoparticles synthesized by the coprecipitation method (sample 1) and the diol method (sample 2), and one cobalt oxide $\left(\mathrm{CoO}_{\mathrm{x}}\right)$ synthesized by the diol method. Figure $1 \mathrm{~A}-\mathrm{C}$ shows the TEM of the different nanoparticles, presenting an average size of $11.6 \pm 4.2,9.5 \pm 3.3$, and $8.0 \pm 1.6 \mathrm{~nm}$ for $\mathrm{TiO}_{2}$, and $\mathrm{Fe}_{\mathrm{x}} \mathrm{O}_{\mathrm{y}}$ samples 1 and 2 respectively (see Fig. $\mathrm{S} 1$ for the size distribution plot). $\mathrm{CoO}_{\mathrm{x}}$ nanoparticles were not visualized in TEM probably due to their very small size.

The exterior layers (inner and outer) of the masks showed a non-woven structure formed by randomly oriented filaments with an average thickness of 

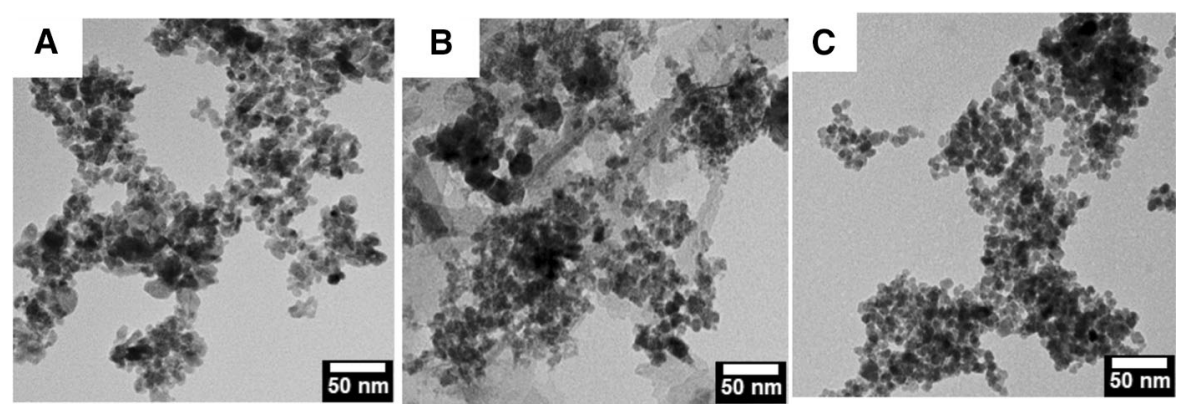

Fig. 1 TEM images of synthesized nanoparticles: $\mathbf{A} \mathrm{TiO}_{2}$ nanoparticles, $\mathbf{B} \mathrm{Fe}_{\mathrm{x}} \mathrm{O}_{\mathrm{y}}$ sample 1, synthesized by co-precipitation, and C $\mathrm{Fe}_{\mathrm{x}} \mathrm{O}_{\mathrm{y}}$ sample 2 synthesized by the diol-based method
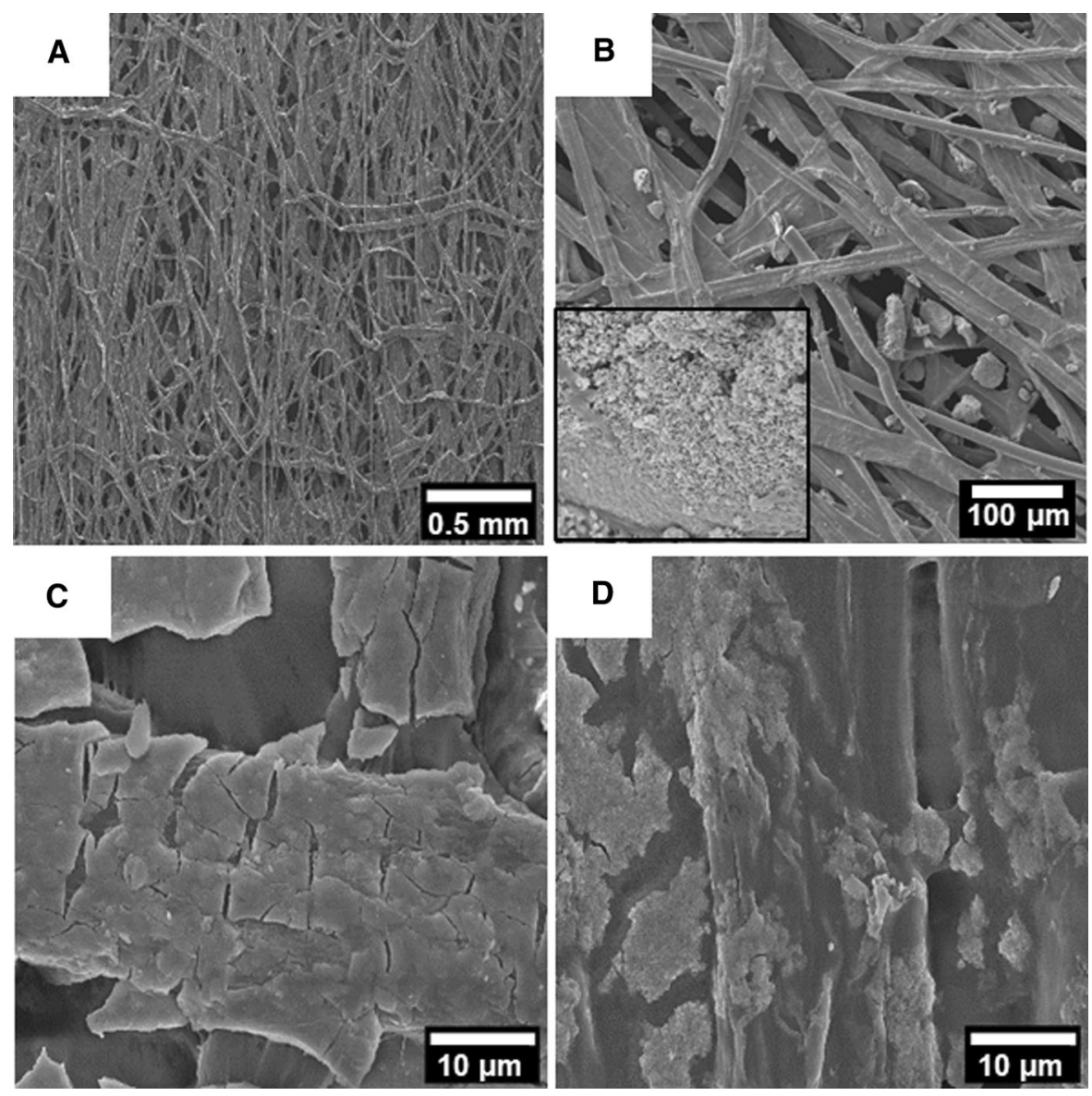

Fig. 2 SEM images of the catalytic substrates. A non-woven cellulose obtained from the mask without any treatment. B Substrate loaded with $\mathrm{TiO}_{2}$ nanoparticles, and inset showing a zoom-in area completely coated with nanoparticles.

C Substrate loaded with $\mathrm{Fe}_{\mathrm{x}} \mathrm{O}_{\mathrm{y}}$ - sample 1 nanoparticles with high surface coating. D) Substrate loaded with $\mathrm{Fe}_{\mathrm{x}} \mathrm{O}_{\mathrm{y}}$ - sample 2 nanoparticles exhibiting low surface coating

$18.7 \mu \mathrm{m}$ (Fig. S4) and a relatively smooth surface as shown in the SEM image of Fig. 2A. The nanoparticle-functionalized mask was obtained by incubating (impregnation process) the cellulose substrate in a

concentrated solution of nanoparticles followed by a cleaning procedure to remove non-attached nanoparticles (see materials and methods). After incubation, a layer formed of islands of nanoparticles was 
appreciated on the sheet filament surfaces (Fig. 2B, D) with a homogenous distribution through the film (observed by SEM inspection in different regions and visually with a homogenous distribution of color). This good adsorption was expected, given the hydrophilic nature of the cellulose sheet and the large amount of hydroxyl groups. Nevertheless, highly different patterns were observed. For $\mathrm{TiO}_{2}$ The nanoparticles appeared in small aggregates intercalated in the fibers and small areas with highly covered fibers (Fig. 2B and inset respectively). For $\mathrm{Fe}_{\mathrm{x}} \mathrm{O}_{\mathrm{y}}$, the fibers showed a more homogeneous coverage but with different coating surface areas (Fig. 2C, D).

$\mathrm{TiO}_{2}$ nanoparticles were analyzed by XRD showing its crystalline structure corresponding mainly to anatase phase with a contribution of $65 \%$, while the other phases were minority, rutile $23 \%$ and brookite $12 \%$ (Fig. S2). From the diffractogram and applying the Scherrer's formula at the (100) peak, a crystalline grain size of $7.6 \mathrm{~nm}$ can be extracted, slightly lower than the one obtained by TEM and indicative of a high number of single crystal nanoparticles. Additionally, using diffuse reflectance spectrometry, a bandgap of $3.1 \mathrm{eV}$ can be extracted (Fig. S3), a typical value for $\mathrm{TiO}_{2}$, which folds between the 3.05 and $3.2 \mathrm{eV}$ for rutile and anatase phase respectively (Hanaor and Sorrell 2010; Sahu and Murty 2016).
To evaluate the crystalline phase of $\mathrm{Fe}_{\mathrm{x}} \mathrm{O}_{\mathrm{y}}$ and therefore their catalytic capabilities (Tokoro et al. 2018) the samples were checked by XPS (see Fig. 3A and $\mathrm{B}$ ), and fitted either to only $\mathrm{Fe}^{3+}$ (for the case of $\mathrm{Fe}_{2} \mathrm{O}_{3}$ ) or both $\mathrm{Fe}^{3+}$ and $\mathrm{Fe}^{2+}$ (for the case of $\mathrm{Fe}_{3} \mathrm{O}_{4}$ ). The experimental data were fit in the $\mathrm{Fe}(2 \mathrm{p})$ region of binding energies given a ratio of $\mathrm{Fe}^{2+} / \mathrm{Fe}^{3+}$ of 0.47 and 0.512 . Note here, that despite the presence of a satellite peak in the $720 \mathrm{eV}$ region, typically attributed to $\gamma-\mathrm{Fe}_{2} \mathrm{O}_{3}$, the envelope does not generate a good fit to the experimental data. Therefore, the ratio $\mathrm{Fe}^{2+} / \mathrm{Fe}^{3+}$, close to 0.5 , and its better fit suggest a majority of $\mathrm{Fe}_{3} \mathrm{O}_{4}$ crystalline phase, which should show higher activity than other crystalline phases (Chen et al. 2012). Finally, the solution containing $\mathrm{CoO}_{x}$ didn't show any crystalline peak in XRD, probably due to its difficult purification and high presence of partially reacted reagents. XRD was conducted to confirm whether or not changes in the crystalline structure of cellulosic support took place during the metal oxide nanoparticle decoration process. As shown in Fig. 3C, neat cellulose was characterized by three wide diffraction peaks centered at $2 \theta=15.1,17.5$, and $22.7^{\circ}$ arising from the (1-10), (110), and (200) crystal planes of cellulose I (JCPDS card no. 00-050-2241), respectively ( $\mathrm{Xu}$ et al. 2013). The XRD pattern of metal-oxide decorated samples was also dominated by
Fig. 3 XPS spectra of $\mathrm{Fe}_{\mathrm{x}} \mathrm{O}_{\mathrm{y}}$ corresponding to the $\mathrm{Fe} 2 \mathrm{p}$ region for samples 1 (A) and 2 (B). Markers represent the measured spectrum, orange line the peaks to fit according to ref (Yamashita and Hayes 2008) and black solid line the fitting envelope. The $\mathrm{Fe}^{3+} / \mathrm{Fe}^{2+}$ obtained after the fitting corresponds to 2.13 for sample 1, and 1.95 for sample 2. In agreement with a majority of $\mathrm{Fe}_{3} \mathrm{O}_{4}$ phase.

C) XRD patterns and D) representative tensile stressstrain curves of the samples. MD: machine direction; TD: transverse direction
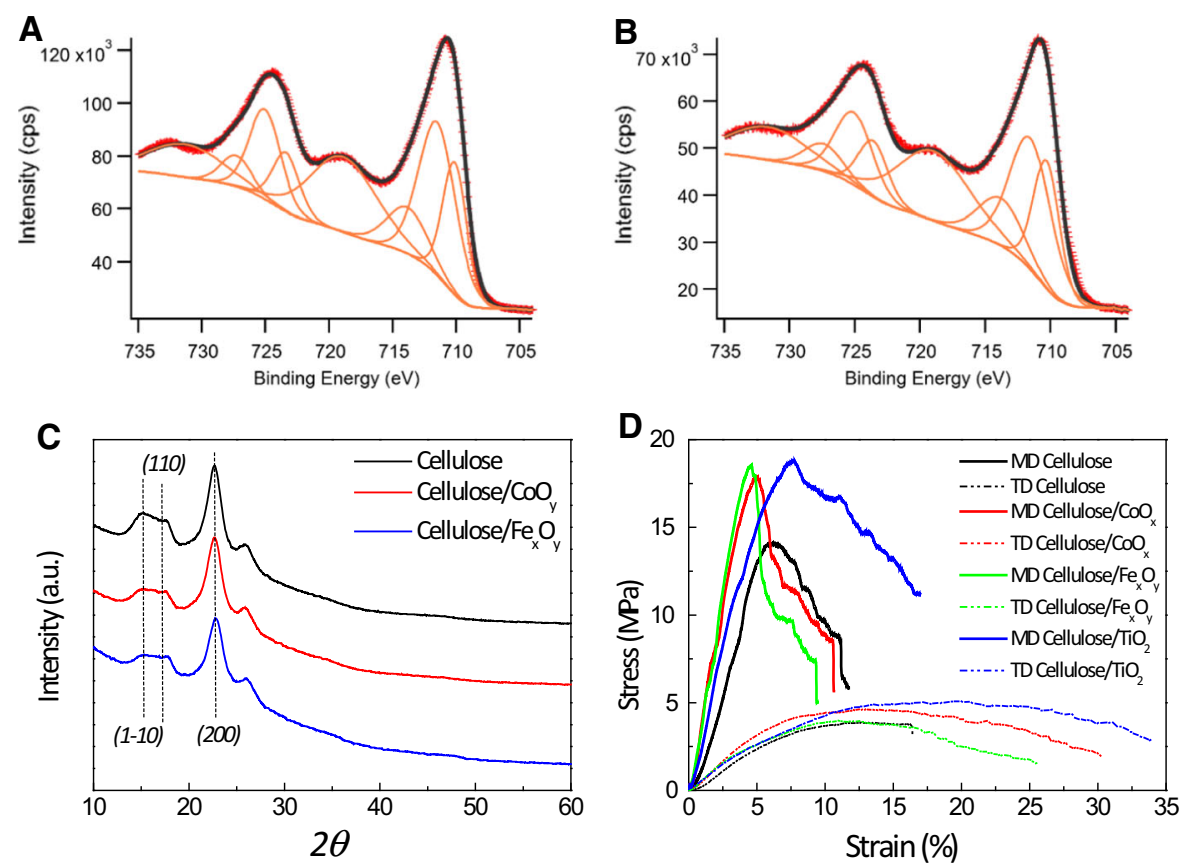
those characteristic reflections, indicating that the sample preparation process was mild enough to maintain the crystalline structure of the cellulosic support unchanged. The fact that no marked new diffraction peaks were observed suggests a low concentration of deposited metal oxide nanoparticles.

Mechanical properties of synthesized membranes were determined under uniaxial tensile testing mode to predict the capacity of such hybrid materials to withstand external stresses under application as catalysts. During fabrication, cellulose fabric is submitted to a stretching process in two orthogonal directions, producing biaxially oriented fabrics with anisotropic structural and mechanical properties (Lizundia et al. 2016; Kröling et al. 2018). Therefore, Fig. 3D summarizes obtained representative tensile stress-strain curves for the two orthogonal directions; machine direction (MD) which correlates with the stretching direction during cellulosic fabric preparation, and its transverse direction (TD). To enable an accurate comparison, Table 1 displays the main average and standard deviation mechanical property values in the MD direction, including Young's modulus $(E)$, elongation and stress at yield $\left(\varepsilon_{y}, \sigma_{y}\right)$ and the elongation and stress at break $\left(\varepsilon_{b}, \sigma_{b}\right)$. Neat cellulosic fabric shows a semiductile behavior with Young's modulus of $339 \pm 88 \mathrm{MPa}, \sigma_{y}$ of $14.3 \pm 1.1 \mathrm{MPa}$ and an elongation at break of $11.0 \pm 0.8 \%$ (the modulus decreases to $51 \mathrm{MPa}$ while $\varepsilon_{b}$ reaches $\sim 18 \%$ in the TD). Obtained $E$ is comparable to soft polyesters ( $E$ : 0.3-1 GPa) (Ribeiro et al. 2021), or natural materials such as leather or wood (E: 0.1-1 GPa) (AL-Oqla and Salit 2017), which ensures an adequate mechanical adaptability of the membranes when in use. Overall, metal oxide nanoparticle decoration increases both Young's modulus and tensile strength up to 550-570 MPa and 17.8-18.1 MPa, respectively, suggesting a mechanically reinforcing effect of inorganic nanoparticles. In spite of the stiffening effect provided by inorganic nanoparticles, the ductility remains barely unchanged, keeping the elongation at break above $10 \%$. Importantly, achieved $\varepsilon_{b}$ values are larger than results obtained for other porous materials such as Celgard 2400 (based on a petroleum-derived polymer) or glass microfiber filters, with elongations at break of 3 and $5.8 \%$, respectively (Tian et al. 2019; Gonçalves et al. 2019). Such adequate ductility ensures that the membranes will not break apart when applied as catalytically active free-standing hybrid materials.

Photocatalytic performance for the degradation of dyes

The photocatalytic properties of the $\mathrm{TiO}_{2}$-functionalized mask were assayed in the degradation of the dye methylene blue. The initial absorption (in dark) of methylene blue and the subsequent photocatalytic degradation (under UV light) was monitored by UVVis spectroscopy following the methylene blue main peak at $664 \mathrm{~nm}$ corresponding to the mesomer II (Fernández-Pérez and Marbán 2020). Figure 4A shows the decrease of solution absorbance due to the absorption of methylene blue by the cellulose substrate when the substrate was immersed in its solution. The cellulosic natural porous structure together with its inherently hydrophilic nature provided by the many $-\mathrm{OH}$ groups induced a considerable absorption of the dye that accounted for more than $60 \%$. This marked absorption favors the posterior catalysis by bringing the pollutant to the region where photocatalytic nanoparticles are located. The absorption process was finished between 2 and $3 \mathrm{~h}$ after the immersion of the substrate (Fig. 3A), and no further changes were observed even after long periods (more than 1 day). Once the absorption was finished the sample was exposed to UV-light with a light power of 50

Table 1 Main representative parameters of tensile test for cellulose/metal oxide nanoparticle membranes. E: Young's modulus; $\varepsilon_{\mathrm{y}}$ : elongation at yield; $\sigma_{\mathrm{y}}$ : stress at yield; $\varepsilon_{\mathrm{b}}$ : elongation at break; $\sigma_{\mathrm{b}}$ : stress at break

\begin{tabular}{lrrrrr}
\hline & \multicolumn{1}{c}{$E(\mathrm{MPa})$} & \multicolumn{1}{c}{$\varepsilon_{Y}(\%)$} & $\sigma_{y}(\mathrm{MPa})$ & $\varepsilon_{b}(\%)$ & $\sigma_{b}(\mathrm{MPa})$ \\
\hline Neat cellulose & $340 \pm 90$ & $6.4 \pm 1.3$ & $14.3 \pm 1.1$ & $11.0 \pm 0.8$ & $8.6 \pm 0.7$ \\
Cellulose $/ \mathrm{CoO}_{\mathrm{y}}$ & $550 \pm 100$ & $5.1 \pm 0.2$ & $17.8 \pm 1.0$ & $10.8 \pm 1.1$ & $9.1 \pm 1.5$ \\
Cellulose $/ \mathrm{Fe}_{\mathrm{x}} \mathrm{O}_{\mathrm{y}}$ & $570 \pm 70$ & $4.5 \pm 0.1$ & $18.1 \pm 1.5$ & $9.9 \pm 0.6$ & $7.8 \pm 0.4$ \\
Cellulose $/ \mathrm{TiO}_{2}$ & $430 \pm 70$ & $7.8 \pm 0.2$ & $18.9 \pm 4.2$ & $17.3 \pm 3.3$ & $8.9 \pm 0.4$ \\
\hline
\end{tabular}



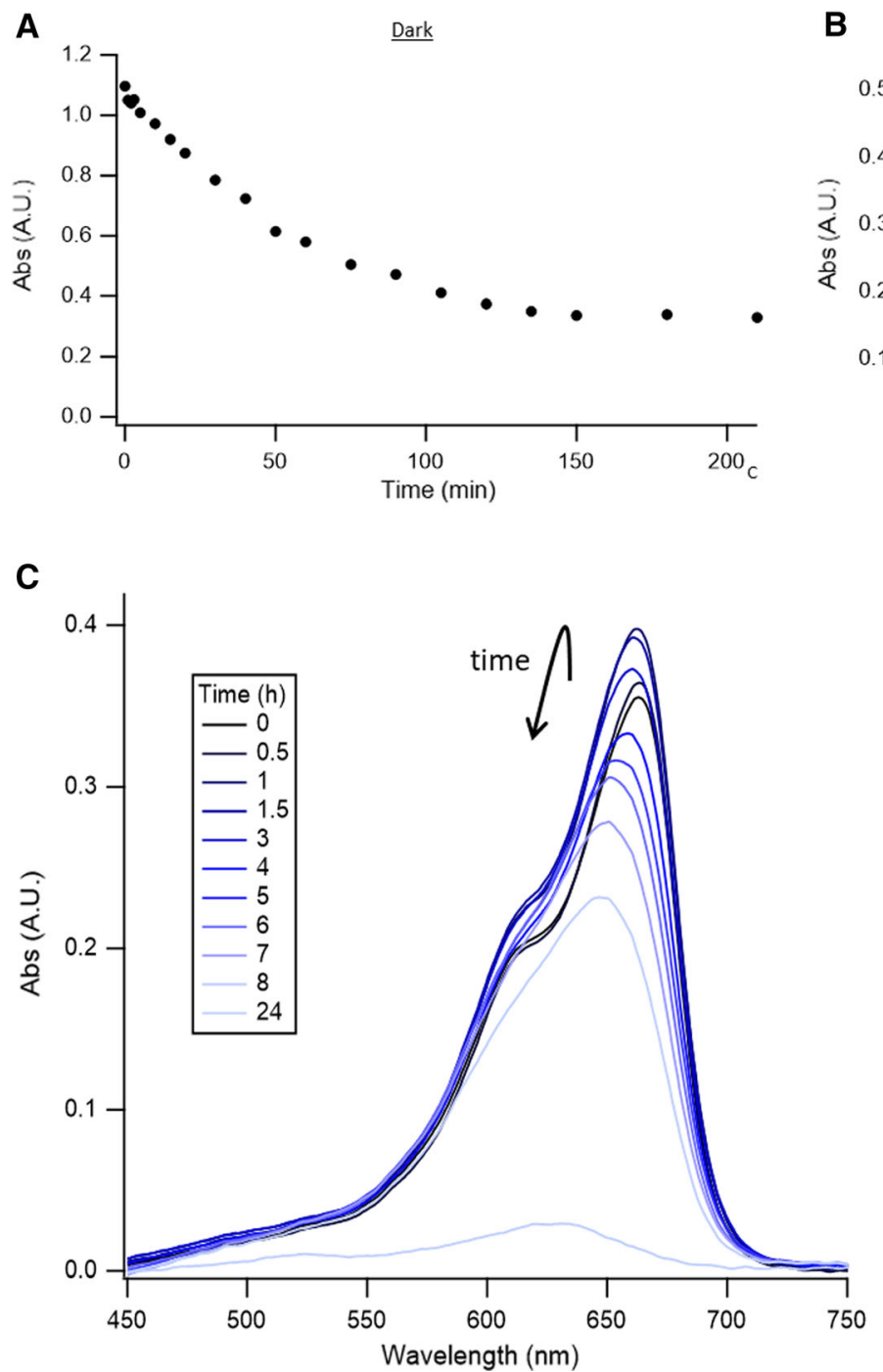
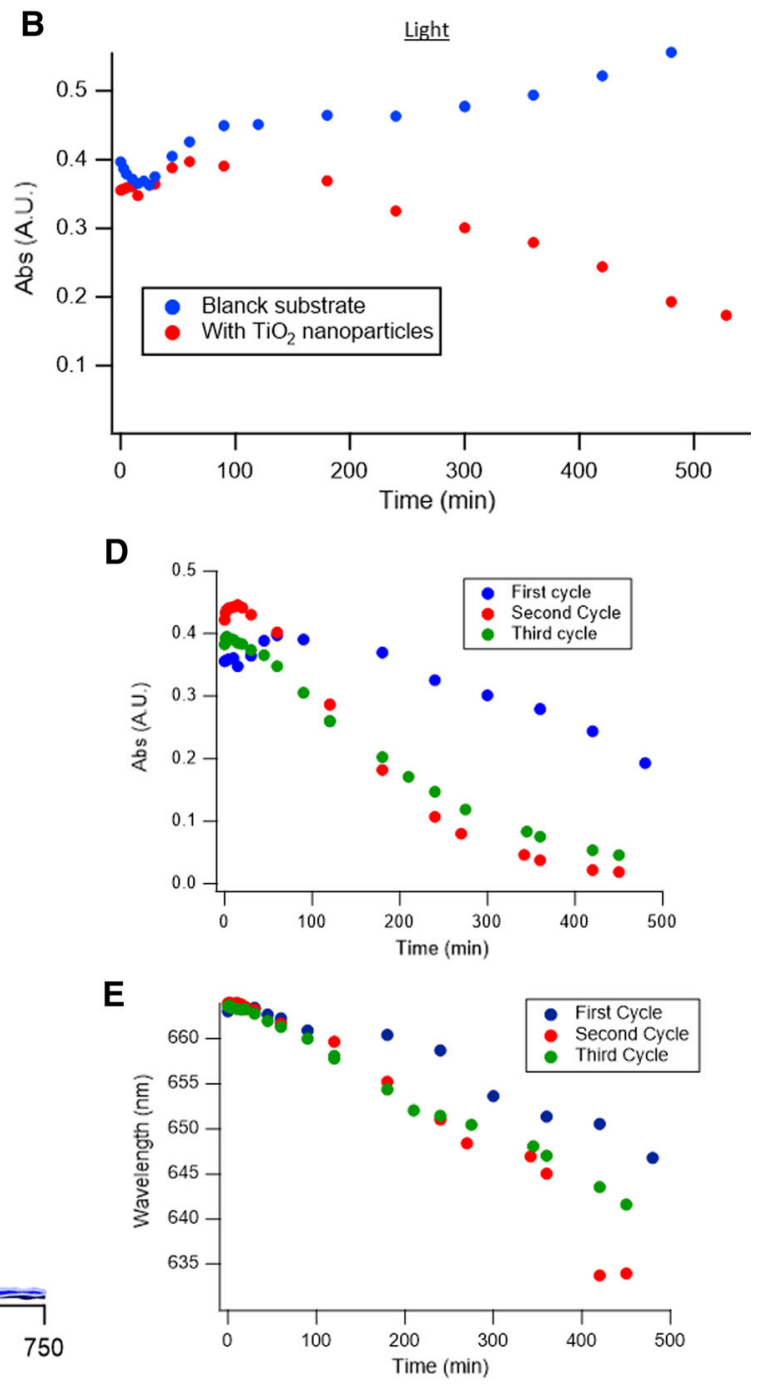

Fig. 4 Photocatalytic degradation of methylene blue by $\mathrm{TiO}_{2}-$ modified cellulose substrates. The extent of catalysis was analyzed by following the maximum absorbance of methylene blue $(664 \mathrm{~nm})$. (A) Variation of absorbance of methylene blue in illumination absence. (B) Variation of absorbance under UVillumination for substrates with (red) and without (blue) $\mathrm{TiO}_{2}$

$\mathrm{mW} \cdot \mathrm{cm}^{-2}$ which promotes the generation of electronhole pairs that migrate to the surface of the nanoparticle and generate the simultaneous reduction of oxygen and oxidation of water generating reactive species that degrade the organic pollutants close to their surface (Zangeneh et al. 2015; Schreck and Niederberger 2019). The formation of high levels of reactive oxygen species (ROS) during UV illumination of filter paper/ $\mathrm{TiO}_{2}$ nanowires has been recently nanoparticles. (C) Spectra of the methylene blue solution at different illumination times, showing an initial increase and a posterior decrease of absorbance. (D) and (E) Absorbance and wavelength at the maximum respectively in a 3 cycles reusability test

observed by Horváth et al. (2020). These ROS are capable of degrading pollutants, including MB.

Figure 4B (in red) shows the decrease in absorbance due to the photocatalytic degradation of the dye. Interestingly the absorbance exhibits an initial increase, which is attributed to light-induced desorption and has been previously observed in $\mathrm{TiO}_{2}$ photocatalysis (Xu et al. 2014). In fact, when a control substrate is used (Fig. 4B, in blue), a continuous increase in absorbance is observed, indicating that 
light-induced desorption is produced at the cellulose matrix. For long times (1 day), the reaction was complete for the $\mathrm{TiO}_{2}$-containing substrate $(\mathrm{A} \approx$ 0.01), while for the blank substrate only a small decrease of absorbance was observed $(\mathrm{A} \approx 0.3$, compared with the 0.4 that appeared at the beginning of the illumination) due to methylene blue photobleaching. Together with the decrease of absorbance in the photocatalysis, there was also a concomitant blue-shift of the main peak by $20 \mathrm{~nm}$ after $8 \mathrm{~h}$ of catalysis, (see corresponding UV-Vis spectra in Fig. 4C) indicating chemical changes produced in the degradation of the molecule

The Langmuir-Hinshelwood kinetic model has proven to be useful to describe the kinetics of photocatalytic reactions of pollutants in aqueous systems (Petukhov 1997; Yonar et al. 2006; Chiou et al. 2008). According to Fig. S5 and Eq. 1, a $k_{a p p}$ value of $2.6 \times 10^{-3} \cdot \mathrm{min}^{-1}$ is obtained for the first cycle. As summarized in Table 2 , this conversion rate is above the $k_{a p p}$ reported for other related systems, with values of $1.1 \times 10^{-3} \cdot \mathrm{min}^{-1}$ for $\mathrm{TiO}_{2}$-nanoparticles immobilized within a cellulose nanofibre monolith (MO decomposition) (Lucchini et al. 2018), or $0.9 \times 10^{-3} \cdot \mathrm{min}^{-1}$ for $\mathrm{TiO}_{2}$-nanoparticles immobilized onto a macroporous $\mathrm{SiO}_{2}$ matrix (MO decomposition) (Marques et al. 2021). Although larger $k$ values can be obtained by dispersion $\mathrm{TiO}_{2}$ nanoparticles into the pollutant $\left(71 \times 10^{-3} \cdot \mathrm{min}^{-1}\right.$ for $\mathrm{MB}$ under $254 \mathrm{~nm}$ irradiation (Chen and Hsu 2021). $18 \times 10^{-3} \cdot \mathrm{min}^{-1}$ for MB under $365 \mathrm{~nm}$ irradiation (Azeez et al. 2018), or $2.8 \times 10^{-3} \cdot \mathrm{min}^{-1}$ for $\mathrm{MO}$ under UV irradiation) (Zheng et al. 2019). the practical implementation of dispersed catalytically active nanoparticles bears serious limitations due to their difficult removal from the media.

To study the reusability of the substrate, the same substrate was applied in two more photocatalytic degradation cycles. The substrate produced the same amount of absorption (in dark) in all experiments. Under illumination, however, the photocatalytic performance improved after the second cycle (see Fig. 4D and E for peak absorbance and wavelength at the maximum respectively). Similar performance to the second cycle was produced during the third cycle, indicating good reusability of the substrate $\left(k_{\text {app }}\right.$ of 8.2 and $5.2 \times 10^{-3} \cdot \mathrm{min}^{-1}$ for the second and third cycles, respectively). The dissimilar behavior produced in the first cycle can be rationalized due to a photocatalytic cleaning of the surface of the $\mathrm{TiO}_{2}$ nanoparticles and removal of sub-products generated during the synthesis and processing steps (McGuinness et al. 2016; Adachi et al. 2018). Importantly, the chemical structure of the cellulose substrate was not damaged or altered after photocatalytic reactions as the fingerprint FTIR spectrum of cellulose (broad $\mathrm{O}-\mathrm{H}$ vibration band at $3600-3200 \mathrm{~cm}^{-1}$, narrow $\mathrm{C}-\mathrm{H}$ band at $2902 \mathrm{~cm}^{-1}$ or the $\mathrm{C}-\mathrm{O}-\mathrm{C}$ bending at $1160 \mathrm{~cm}^{-1}$ )

Table 2 Comparison of different photocatalysts and the obtained apparent rate constant $(k)$. MB: methylene blue; MO: methyl orange

\begin{tabular}{|c|c|c|c|c|c|}
\hline Photocatalyst & Pollutant & Dispersed/immobilized & Radiation $(\lambda, h v)$ & $k\left(\min ^{-1}\right)$ & References \\
\hline $\mathrm{TiO}_{2}$ & MB & $\begin{array}{l}\text { Immobilized (cellulose non- } \\
\text { woven) }\end{array}$ & $365 \mathrm{~nm}\left(400 \mathrm{~W} \cdot \mathrm{m}^{-2}\right)$ & $2.6-8.2 \times 10^{-3}$ & This work \\
\hline $\begin{array}{l}\mathrm{TiO}_{2} \text { (non-aqueous } \\
\text { sol-gel) }\end{array}$ & MO & $\begin{array}{l}\text { Immobilized (macroporous } \\
\mathrm{SiO}_{2} \text { ) }\end{array}$ & $\begin{array}{l}\text { Solar simulator, } 1 \text { sun } \\
\quad\left(1000 \mathrm{~W} \cdot \mathrm{m}^{-2}\right)\end{array}$ & $0.9 \times 10^{-3}$ & $\begin{array}{l}\text { (Marques et al. } \\
\text { 2021) }\end{array}$ \\
\hline $\begin{array}{l}\mathrm{TiO}_{2} \text { (non-aqueous } \\
\text { sol-gel) }\end{array}$ & MO & $\begin{array}{l}\text { Immobilized (cellulose } \\
\text { nanofibre monolith) }\end{array}$ & $\begin{array}{l}\text { Solar simulator, } 1 \text { sun } \\
\quad\left(1000 \mathrm{~W} \cdot \mathrm{m}^{-2}\right)\end{array}$ & $1.1 \times 10^{-3}$ & $\begin{array}{l}\text { (Lucchini et al. } \\
\text { 2018) }\end{array}$ \\
\hline $\mathrm{TiO}_{2}(\mathrm{P} 25)$ & MB & $\begin{array}{l}\text { Dispersed (unknown } \\
\text { concentration) }\end{array}$ & $254 \mathrm{~nm}(36 \mathrm{~W})$ & $71 \times 10^{-3}$ & $\begin{array}{l}\text { (Chen and Hsu } \\
\text { 2021) }\end{array}$ \\
\hline $\begin{array}{l}\mathrm{TiO}_{2} \text { (non-aqueous } \\
\text { sol-gel) }\end{array}$ & MB & Dispersed $\left(100 \mathrm{mg} \cdot \mathrm{L}^{-1}\right)$ & $365 \mathrm{~nm}(6 \mathrm{~W})$ & $18 \times 10^{-3}$ & $\begin{array}{l}\text { (Azeez et al. } \\
\text { 2018) }\end{array}$ \\
\hline $\begin{array}{l}\mathrm{TiO}_{2} \text { (non-aqueous } \\
\text { sol-gel) }\end{array}$ & MO & Dispersed $\left(500 \mathrm{mg} \cdot \mathrm{L}^{-1}\right)$ & Solar illumination & $2.8 \times 10^{-3}$ & $\begin{array}{l}\text { (Zheng et al. } \\
\text { 2019) }\end{array}$ \\
\hline $\begin{array}{l}\mathrm{TiO}_{2} \text { (solvethermal- } \\
\text { calcination) }\end{array}$ & MO & Dispersed $\left(500 \mathrm{mg} \cdot \mathrm{L}^{-1}\right)$ & Visible light (300 W) & $1.6 \times 10^{-3}$ & $\begin{array}{l}\text { (Wang et al. } \\
\text { 2018a) }\end{array}$ \\
\hline
\end{tabular}


remained unchanged after methylene blue soaking and the 3 photocatalytic cycles (Fig. S6) (Nguyen et al. 2018). Altogether, results suggest good reusability of the catalytic materials as neither activity decrease nor substrate degradation occurs.

\section{Peroxidase-like catalysis}

A Section $\left(4 \mathrm{~cm}^{2}\right)$ of the catalytic cellulose substrate was introduced in a glass cuvette containing a solution of $\mathrm{TMB}$ at $\mathrm{pH}=4.66$, and then a small quantity of $\mathrm{H}_{2} \mathrm{O}_{2}$ was added to start the reaction. The solution changed from transparent to blue due to the appearance of a peak at $654 \mathrm{~nm}$ (Fig. 5A) of the generated oxidized TMB. The three substrates showed a clear catalytic effect as summarized in Fig. 5B (see the fitting in Fig. S7). Considering the $\mathrm{H}_{2} \mathrm{O}_{2}$ degradation, we extrapolated the peroxidase-like catalytic activity rate of fabricated nanozymes. Values of $k=5.6 \times 10^{-2} \mathrm{~min}^{-1}, \quad 1.2 \times 10^{-2} \mathrm{~min}^{-1}, \quad$ and $1.8 \times 10^{-3} \mathrm{~min}^{-1}$ are achieved for $\mathrm{Fe}_{\mathrm{x}} \mathrm{O}_{\mathrm{y}}$ (sample 1), $\mathrm{Fe}_{\mathrm{x}} \mathrm{O}_{\mathrm{y}}$ (sample 2) and $\mathrm{CoO}_{\mathrm{x}}$, respectively, showing a peroxidase-like catalytic kinetic constant for $\mathrm{Fe}_{\mathrm{x}} \mathrm{O}_{\mathrm{y}}$ one order-of-magnitude higher than $\mathrm{CoO}_{\mathrm{x}}$ for the TMB oxidation when $\mathrm{H}_{2} \mathrm{O}_{2}$ acts as oxidant. An interesting advantage of developed materials over other cellulose-supported nanohybrids is their easy of fabrication in comparison with more complex systems relying on multicomponent-materials (Hou et al. 2021), which show a robust peroxidase-like activity but are complex to fabricate.

As mentioned above, both sample 1 and sample 2 the $\mathrm{Fe}_{\mathrm{x}} \mathrm{O}_{\mathrm{y}}$ showed a similar composition corresponding mainly to the magnetite phase. Furthermore, sample 2 showed a slightly smaller size, 8.0 instead

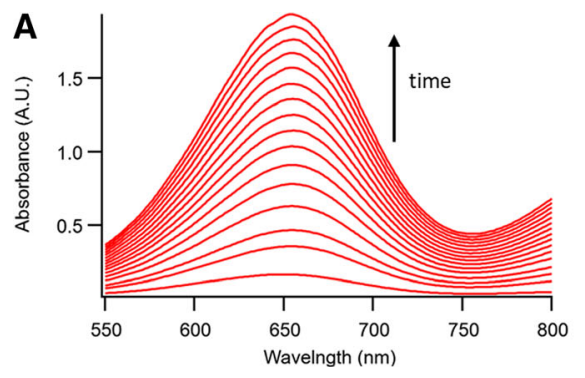

Fig. 5 Peroxidase-like catalytic kinetic of different cellulosefunctionalized substrates with nanoparticles of $\mathrm{Fe}_{\mathrm{x}} \mathrm{O}_{\mathrm{y}}$ (samples 1 and 2) and $\mathrm{CoO}_{\mathrm{x}}$. A Spectra of the reaction at different time intervals showing the appearance of an intense band of $9.5 \mathrm{~nm}$, which should favor its catalytic performance given its larger surface area. ICP analysis of the three different substrates was then performed to account for the possible concentration differences. The ICP showed concentrations, in terms of metal element per substrate area, of $90.5,30.9$, and $3.4 \mu \mathrm{g} \cdot \mathrm{cm}^{2}$ which corresponds to $4.2,1.6$, and $0.17 \%$ for $\mathrm{Fe}_{\mathrm{x}} \mathrm{O}_{\mathrm{y}}$ sample 1 and 2 , and $\mathrm{CoO}_{\mathrm{x}}$ respectively. This was in agreement with what was visually observed by SEM (Fig. 2), where high coverage was observed for $\mathrm{Fe}_{\mathrm{x}} \mathrm{O}_{\mathrm{y}}$ sample 1, nanoparticle islands for $\mathrm{Fe}_{\mathrm{x}} \mathrm{O}_{\mathrm{y}}$ sample 2 , and barely any nanoparticle for $\mathrm{CoO}_{\mathrm{x}}$. The high difference in nanoparticle load seems to be the main mechanism for the notable differences in catalytic performance. The different chemical nature or type of nanoparticle synthesis is therefore affecting how the nanoparticles are absorbed in the cellulose substrate and therefore it is the main responsible for the efficiency of the nanozyme-based catalytic substrates. Interestingly, the cellulose $/ \mathrm{Fe}_{\mathrm{x}} \mathrm{O}_{\mathrm{y}}$ samples could be also applied in additional catalytic reactions, such as those aimed for organic synthesis (Kamel and Khattab 2021).

Developed materials do not only show efficient activities towards the degradation of contaminants of emerging concern or marked peroxidase-like activities, but rely on well-known biocompatible nanomaterials. In fact, iron oxide and $\mathrm{TiO}_{2}$ are FDA-approved for use as pharmaceutical and food additives. Precisely, iron oxide nanoparticles, widely used in biomedical applications and show a relatively low cytotoxic effect, while $\mathrm{TiO}_{2}$ nanoparticles are broadly used in many consumables such as sunscreens, food additives or coatings (Yildirimer et al. 2011). However, some adverse cytotoxic effects have been

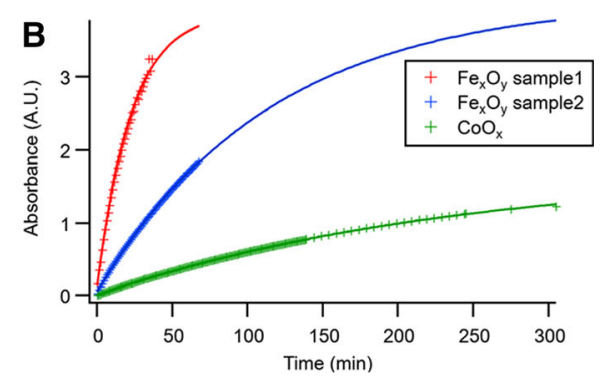

corresponding to the oxidation of TMB by $\mathrm{H}_{2} \mathrm{O}_{2}$ catalyzed by the substrate. B Absorbance at $664 \mathrm{~nm}$ as a function of time for the three different substrates 
reported for cobalt oxide, which can release Co ions that can result in generating oxidative stress (Cavallo et al. 2015). The biocompatibility of used metal oxide nanoparticles coupled with the innocuous character of cellulose makes these materials interesting for biomedical applications, although special care should be paid to the possible allergic reactions against human skin (Larsen et al. 2010; Cho et al. 2012; Horie et al. 2015; Ngobili and Daniele 2016; Lim et al. 2021).

\section{Conclusions}

The aim of this work was to develop catalytically active free-standing materials using porous cellulosic substrates that originate from waste. Accordingly, after the incorporation of $\mathrm{TiO}_{2}, \mathrm{CoO}_{\mathrm{x}}$, and $\mathrm{Fe}_{\mathrm{x}} \mathrm{O}_{\mathrm{y}}$ nanoparticles onto the surface of the cellulose nonwoven layer of surgical masks, materials with proven catalytic activity were obtained. Microscopic observations revealed a homogeneous coating of inorganic nanoparticles onto the three-dimensional porous structure of the cellulosic membranes by a simple and implantable method. A photo-initiated decomposition of organic pollutants from an aqueous solution was demonstrated by the cellulosic mask/ $/ \mathrm{TiO}_{2}$ system, which effectively decomposes methylene blue under UV illumination. Additionally, the cellulosic mask/ $\mathrm{Fe}_{\mathrm{x}} \mathrm{O}_{\mathrm{y}}$ system demonstrated a good peroxidase-like activity, opening the door to advanced applications such as electrochemical sensors for hydrogen peroxide. In comparison with previous works based on dispersed nanoparticles, this approach has the advantage that relies on catalytically active nanoparticles attached onto a hydrophilic free-standing porous cellulosic substrate. This feature avoids nanoparticle aggregation during the catalytic reactions, circumvents medium contamination issues arising from nanoparticle release effects, and enables an easy handling of the material and its subsequent reuse for several cycles. The synthetic procedure reported here holds great potential for the development of catalytically active materials by a greener-fabrication method as it can be easily extended to the upcycling of other related systems, either cellulosic or not. This is particularly relevant given the large amount of accumulated polymeric waste and the widespread efforts in the burgeoning area of catalysis for environmental applications.

Acknowledgments J.R. acknowledges the funding support from the Spanish State Research Agency (AEI) through the project PID2019-106099RB-C43/AEI/10. 13039/5011000 11033. A.E.S. thanks the National Research grants from MINECO, Spain, "Juan de la Cierva" [FJCI-2018-037717] and he is currently on leave from CMRDI. The authors thank for the technical and human support provided by SGIker (UPV/ EHU/ ERDF, EU).

Author contributions E.L. conceived the idea, organized the manuscript writing, and performed the XRD and mechanical assays. A.S. performed the nanoparticle synthesis and prepared the catalytic substrates. F.Z. performed the substrate characterization microscopy (TEM, SEM) and the elemental analysis (ICP). J.R. designed the experiments, performed the photocatalysis and enzyme-like catalysis experiments, and analyzed the results. The manuscript was written and revised by E.L. and J.R.

Funding Open Access funding provided thanks to the CRUECSIC agreement with Springer Nature.

Data availability All the data used to support the findings of this study are included within the article.

\section{Declarations}

Conflict of interest The authors declare no competing financial interest.

Open Access This article is licensed under a Creative Commons Attribution 4.0 International License, which permits use, sharing, adaptation, distribution and reproduction in any medium or format, as long as you give appropriate credit to the original author(s) and the source, provide a link to the Creative Commons licence, and indicate if changes were made. The images or other third party material in this article are included in the article's Creative Commons licence, unless indicated otherwise in a credit line to the material. If material is not included in the article's Creative Commons licence and your intended use is not permitted by statutory regulation or exceeds the permitted use, you will need to obtain permission directly from the copyright holder. To view a copy of this licence, visit http://creativecommons.org/licenses/by/4.0/.

\section{References}

Adachi T, Latthe SS, Gosavi SW et al (2018) Photocatalytic, superhydrophilic, self-cleaning $\mathrm{TiO}_{2}$ coating on cheap, light-weight, flexible polycarbonate substrates. Appl Surf Sci 458:917-923. https://doi.org/10.1016/J.APSUSC. 2018.07.172 
Al-Oqla FM, Salit MS (2017) Materials selection. In: Al-Oqla FM, Salit MS (eds) Materials selection for natural fiber composites. Woodhead Publishing, Sawston

Armentano I, Barbanera M, Carota E, Crognale S, Marconi M, Rossi S, Rubino G, Scungio M, Taborri J, Calabrò G (2021) Polymer materials for respiratory protection: processing, end use, and testing methods. ACS Appl Polym Mater 3:531-548. https://doi.org/10.1021/acsapm.0c01151

Awan F, Islam MS, Ma Y, Yang C, Shi Z, Berry RM, Tam KC (2018) Cellulose canocrystal-ZnO nanohybrids for controlling photocatalytic activity and UV protection in cosmetic gormulation. ACS Omega 3:12403-12411. https:// doi.org/10.1021/acsomega.8b01881

Azeez F, Al-Hetlani E, Arafa M, Abdelmonem Y, Nazeer AA, Amin MO, Madkour M (2018) The effect of surface charge on photocatalytic degradation of methylene blue dye using chargeable titania nanoparticles. Sci Rep 8:7104. https:// doi.org/10.1038/s41598-018-25673-5

Ben M, Gunday PM, Gerba CP, Sobsey MD, Linden KG (2021) UV Inactivation of SARS-CoV-2 across the UVC spectrum: $\mathrm{KrCl}^{*}$ rxcimer, mercury-vapor, and light-emittingdiode (LED) sources. Appl Environ Microbiol 87:e01532e1621. https://doi.org/10.1128/AEM.01532-21

Bilgi E, Homan Gokce E, Bayir E, Sendemir A, Ozer KO, Tuna EEH (2021) Bacterial cellulose based facial mask with antioxidant property and high moisturizing capacity. Cellulose 28:10399-10414. https://doi.org/10.1007/s10570021-04106-z

Cano-Casanova L, Amorós-Pérez A, Ouzzine M, Lillo-Ródenas MA, Román-Martínez MC (2018) One step hydrothermal synthesis of $\mathrm{TiO}_{2}$ with variable $\mathrm{HCl}$ concentration: detailed characterization and photocatalytic activity in propene oxidation. Appl Catal B Environ 220:645-653. https://doi. org/10.1016/J.APCATB.2017.08.060

Cavallo D, Ciervo A, Fresegna AM et al (2015) Investigation on cobalt-oxide nanoparticles cyto-genotoxicity and inflammatory response in two types of respiratory cells. J Appl Toxicol 35:1102-1113. https://doi.org/10.1002/jat.3133

Ccanccapa A, Masiá A, Navarro-Ortega A, Picó Y, Barceló D (2016) Pesticides in the Ebro river basin: occurrence and risk assessment. Environ Pollut 211:414-424. https://doi. org/10.1016/j.envpol.2015.12.059

Chen Y-W, Hsu Y-H (2021) Effects of reaction temperature on the photocatalytic activity of $\mathrm{TiO}_{2}$ with $\mathrm{Pd}$ and $\mathrm{Cu}$ cocatalysts. Catalysts 11(8):966

Chen Z, Yin J-J, Zhou Y-T, Zhang Y, Song L, Song M, Hu S, Gu $N$ (2012) Dual enzyme-like activities of iron oxide nanoparticles and their implication for diminishing cytotoxicity. ACS Nano 6:4001-4012. https://doi.org/10.1021/ nn300291r

Chiou C-H, Wu C-Y, Juang R-S (2008) Influence of operating parameters on photocatalytic degradation of phenol in UV/ TiO2 process. Chem Eng J 139:322-329. https://doi.org/ 10.1016/j.cej.2007.08.002

Cho W-S, Dart K, Nowakowska DJ, Zheng X, Donaldson K, Howie SEM (2012) Adjuvanticity and toxicity of cobalt oxide nanoparticles as an alternative vaccine adjuvant. Nanomedicine 7:1495-1505. https://doi.org/10.2217/nnm. 12.35

Chowdhury H, Chowdhury T, Sait SM (2021) Estimating marine plastic pollution from COVID-19 face masks in coastal regions. Mar Pollut Bull 168:112419. https://doi.org/10. 1016/j.marpolbul.2021.112419

Corrêa HL, Corrêa DG (2021) The Covid-19 pandemic opportunities for Circular Economy practices among sewing professionals in the city of Curitiba-Brazil. Front Sustain 2:2. https://doi.org/10.3389/frsus.2021.644309

Darezereshki E (2010) Synthesis of maghemite $\left(\gamma-\mathrm{Fe}_{2} \mathrm{O}_{3}\right)$ nanoparticles by wet chemical method at room temperature. Mater Lett 64:1471-1472. https://doi.org/10.1016/j. matlet.2010.03.064

DeStefano V, Khan S, Tabada A (2020) Applications of PLA in modern medicine. Eng Regen 1:76-87. https://doi.org/10. 1016/j.engreg.2020.08.002

Dharmaraj S, Ashokkumar V, Hariharan S, Manibharathi A, Show PL, Chong CT, Ngamcharussrivichai C (2021) The COVID-19 pandemic face mask waste: a blooming threat to the marine environment. Chemosphere 272:129601. https://doi.org/10.1016/j.chemosphere.2021.129601

Feng S, Shen C, Xia N, Song W, Fan M, Cowling BJ (2020) Rational use of face masks in the COVID-19 pandemic. Lancet Respir Med 8:434-436. https://doi.org/10.1016/ S2213-2600(20)30134-X

Fernández-Pérez A, Marbán G (2020) Visible light spectroscopic analysis of methylene blue in water; what comes after dimer? ACS Omega 5:29801-29815. https://doi.org/ 10.1021/acsomega.0c03830

Foster HA, Ditta IB, Varghese S, Steele A (2011) Photocatalytic disinfection using titanium dioxide: spectrum and mechanism of antimicrobial activity. Appl Microbiol Biotechnol 90:1847-1868. https://doi.org/10.1007/s00253-011-32137

Foteinis S, Borthwick AGL, Frontistis Z, Mantzavinos D, Chatzisymeon E (2018) Environmental sustainability of light-driven processes for wastewater treatment applications. J Clean Prod 182:8-15. https://doi.org/10.1016/j. jclepro.2018.02.038

Gao L, Fan K, Yan X (2017) Iron oxide nanozyme: a multifunctional enzyme mimetic for biomedicalaApplications. Theranostics 7:3207-3227. https://doi.org/10.7150/thno. 19738

Ghedini E, Pizzolato M, Longo L, Menegazzo F, Zanardo Dm Signoretto M (2021) Which are the main surface disinfection approaches at the time of SARS-CoV-2? Front Chem Eng 2:27. https://doi.org/10.3389/fceng.2020. 589202

Gonçalves R, Lizundia E, Silva MM, Costa CM, LancerosMéndez S (2019) Mesoporous cellulose nanocrystal membranes as battery separators for environmentally safer lithium-ion batteries. ACS Appl Energy Mater 2:3749-3761. https://doi.org/10.1021/acsaem.9b00458

Górak P, Postawa P, Trusilewicz LN, Kalwik A (2020) Cementitious eco-composites and their physicochemical/ mechanical properties in Portland cement-based mortars with a lightweight aggregate manufactured by upcycling waste by-products. J Clean Prod. https://doi.org/10.1016/j. jclepro.2020.125156

Granqvist CG (ed) (1995) Handbook of inorganic electrochromic materials. Elsevier, Amsterdam

Grzelczak M, Vermant J, Furst EM, Liz-Marzán LM (2010) Directed self-assembly of nanoparticles. ACS Nano 4:3591-3605 
Guo S, Han Y, Guo L (2020) Mechanistic study of catalase- and superoxide dismutation-mimic activities of cobalt oxide nanozyme from first-principles microkinetic modeling. Catal Surv from Asia 24:70-85. https://doi.org/10.1007/ s10563-019-09290-4

Hanaor DAH, Sorrell CC (2010) Review of the anatase to rutile phase transformation. J Mater Sci 464(46):855-874. https://doi.org/10.1007/S10853-010-5113-0

Horie M, Stowe M, Tabei M, Kuroda E (2015) Pharyngeal aspiration of metal oxide nanoparticles showed potential of allergy aggravation effect to inhaled ovalbumin. Inhal Toxicol 27:181-190. https://doi.org/10.3109/08958378. 2015.1026618

Horváth E, Rossi L, Mercier C, Lehmann C, Sienkiewicz A, Forró L (2020) Photocatalytic nanowires-based air filter: towards reusable protective masks. Adv Funct Mater 30:2004615. https://doi.org/10.1002/adfm.202004615

Hou C, Fu L, Wang Y, Chen W, Zhang S, Wang J (2021) Coreshell magnetic $\mathrm{Fe}_{3} \mathrm{O}_{4} / \mathrm{CNC} @ \mathrm{MOF}$ composites with peroxidase-like activity for colorimetric detection of phenol. Cellulose 28:9253-9268. https://doi.org/10.1007/s10570021-04117-w

Jiang D, Ni D, Rosenkrans ZT, Huang P, Yan X, Cai W (2019) Nanozyme: new horizons for responsive biomedical applications. Chem Soc Rev 48:3683-3704. https://doi. org/10.1039/C8CS00718G

Kamel S, Khattab TA (2021) Recent advances in cellulose supported metal nanoparticles as green and sustainable catalysis for organic synthesis. Cellulose 28:4545-4574. https://doi.org/10.1007/s10570-021-03839-1

Karpińska J, Kotowska U (2019) Removal of organic pollution in the water environment. Water 11(10):2017. https://doi. org/10.3390/w11102017

Khin MM, Nair AS, Babu VJ, Murugan R, Ramakrishna S (2012) A review on nanomaterials for environmental remediation. Energy Environ Sci 5:8075. https://doi.org/ $10.1039 / \mathrm{c} 2 \mathrm{ee} 21818 \mathrm{f}$

Kirchherr J, Reike D, Hekkert M (2017) Conceptualizing the circular economy: an analysis of 114 definitions. Resour Conserv Recycl 127:221-232. https://doi.org/10.1016/j. resconrec.2017.09.005

Kondo Y, Goto T, Sekino T (2020) Sorption capacity of seaweed-like sodium titanate mats for $\mathrm{Co}^{2+}$ removal. RSC Adv 10:41032-41040. https://doi.org/10.1039/ D0RA06662A

Kröling H, Duchemin B, Dormanns J, Schabel S, Staiger MP (2018) Mechanical anisotropy of paper-based all-cellulose composites. Compos Part A Appl Sci Manuf 113:150-157. https://doi.org/10.1016/j.compositesa.2018.07.005

Kupferschmidt K, Vogel G (2022) Omicron cases are exploding. Scientists still don't know how bad the wave will be. Science. https://doi.org/10.1126/science.acz9940

Larsen ST, Roursgaard M, Jensen KA, Nielsen GD (2010) Nano titanium dioxide particles promote allergic sensitization and lung inflammation in mice. Basic Clin Pharmacol Toxicol 106:114-117. https://doi.org/10.1111/j.17427843.2009.00473.x

Lauria A, Lizundia E (2020) Luminescent carbon dots obtained from polymeric waste. J Clean Prod 262:121288. https:// doi.org/10.1016/j.jclepro.2020.121288
Liang M, Yan X (2019) Nanozymes: from new concepts, mechanisms, and standards to applications. Acc Chem Res 52:2190-2200. https://doi.org/10.1021/acs.accounts. $9 \mathrm{~b} 00140$

Lim J-O, Lee S-J, Kim W-I et al (2021) Titanium dioxide nanoparticles exacerbate allergic airway inflammation via TXNIP upregulation in a mouse model of asthma. Int J Mol Sci 22(18):9924. https://doi.org/10.3390/ijms22189924

Liu P, Zhang H, Feng Y, Shen C, Yang F (2015) Integrating electrochemical oxidation into forward osmosis process for removal of trace antibiotics in wastewater. J Hazard Mater 296:248-255. https://doi.org/10.1016/j.jhazmat.2015.04. 048

Lizundia E, Larrañaga A, Vilas JL, León LM (2016) Threedimensional orientation of poly(l-lactide) crystals under uniaxial drawing. RSC Adv 6:11943-11951. https://doi. org/10.1039/C5RA22680E

Lizundia E, Jimenez M, Altorfer C, Niederberger M, Caseri W (2019) Electroless plating of platinum nanoparticles onto mesoporous cellulose films for catalytically active freestanding materials. Cellulose 26:5513-5527. https://doi. org/10.1007/s10570-019-02463-4

Lizundia E, Costa CM, Alves R, Lanceros-Méndez S (2020) Cellulose and its derivatives for lithium ion battery separators: A review on the processing methods and properties. Carbohydr Polym Technol Appl 1:100001. https://doi.org/ 10.1016/j.carpta.2020.100001

Lucchini M, Lizundia E, Moser S, Niederberger M, Nyström G (2018) Titania-cellulose hybrid monolith for in-flow purification of water under solar illumination. ACS Appl Mater Interfaces 10:29599-29607. https://doi.org/10.1021/ acsami.8b09735

Maharjan A, Dikshit PK, Gupta A, Kim BS (2020) Catalytic activity of magnetic iron oxide nanoparticles for hydrogen peroxide decomposition: optimization and characterization. J Chem Technol Biotechnol 95:2495-2508. https:// doi.org/10.1002/jctb.6431

Manea F, Houillon FB, Pasquato L, Scrimin P (2004) Nanozymes: gold-nanoparticle-based transphosphorylation catalysts. Angew Chem Int Ed 43:6165-6169. https://doi.org/ 10.1002/anie.200460649

Marques AC, Vale M, Vicente D, Schreck M, Tervoort E, Niederberger M (2021) Porous silica microspheres with immobilized titania nanoparticles for in-flow solar-driven purification of wastewater. Glob Challenges 5:2000116. https://doi.org/10.1002/gch2.202000116

McGuinness NB, John H, Kavitha MK, et al (2016) Selfcleaning photocatalytic activity: materials and applications. Photocatalysis: applications. The Royal Society of Chemistry, 204-235

Meng Y, Li W, Pan X, Gadd GM (2020) Applications of nanozymes in the environment. Environ Sci Nano 7:1305-1318. https://doi.org/10.1039/C9EN01089K

Miceli M, Frontera P, Macario A, Malara A (2021) Recovery/ reuse of heterogeneous supported spent catalysts. Catalysts 11(5):591. https://doi.org/10.3390/catal11050591

Mousli F, Khalil AM, Maurel F, Kadri A, Chehimi M (2020) Mixed oxide-polyaniline composite-coated woven cotton fabrics for the visible light catalyzed degradation of hazardous organic pollutants. Cellulose 27:7823-7846. https:// doi.org/10.1007/s10570-020-03302-7 
Mu J, Wang Y, Zhao M, Zhang L (2012) Intrinsic peroxidaselike activity and catalase-like activity of $\mathrm{Co}_{3} \mathrm{O} 4$ nanoparticles. Chem Commun 48:2540-2542. https://doi.org/10. 1039/C2CC17013B

Musino D, Rivard C, Landrot G, Novales B, Rabilloud T, Capron I (2021) Hydroxyl groups on cellulose nanocrystal surfaces form nucleation points for silver nanoparticles of varying shapes and sizes. J Colloid Interface Sci 584:360-371. https://doi.org/10.1016/j.jcis.2020.09.082

Ngobili TA, Daniele MA (2016) Nanoparticles and direct immunosuppression. Exp Biol Med (maywood) 241:1064-1073. https://doi.org/10.1177/ 1535370216650053

Nguyen TD, Sierra E, Eguiraun H, Lizundia E (2018) Iridescent cellulose nanocrystal films: the link between structural colour and Bragg's law. Eur J Phys 39(4):45803

Petukhov AV (1997) Effect of molecular mobility on kinetics of an electrochemical Langmuir-Hinshelwood reaction. Chem Phys Lett 277:539-544. https://doi.org/10.1016/ S0009-2614(97)00916-0

Ribeiro S, Carvalho AM, Fernandes EM et al (2021) Development and characterisation of cytocompatible polyester substrates with tunable mechanical properties and degradation rate. Acta Biomater 121:303-315. https://doi.org/ 10.1016/j.actbio.2020.11.026

Rodríguez-González V, Obregón S, Patrón-Soberano OA et al (2020) An approach to the photocatalytic mechanism in the $\mathrm{TiO}_{2}$-nanomaterials microorganism interface for the control of infectious processes. Appl Catal B Environ 270:118853. https://doi.org/10.1016/j.apcatb.2020.118853

Sahu K, Murty VS (2016) Novel sol-gel method of synthesis of pure and aluminum doped $\mathrm{TiO}_{2}$ nanoparticles. Indian $\mathrm{J}$ Pure Appl Phys 54:485-488

Sakthivel S, Hidalgo MC, Bahnemann DW, Geissen SU, Murugesan V, Vogelpohl A (2006) A fine route to tune the photocatalytic activity of $\mathrm{TiO}_{2}$. Appl Catal B Environ 63:31-40. https://doi.org/10.1016/J.APCATB.2005.08. 011

Schreck M, Niederberger M (2019) Photocatalytic gas phase reactions. Chem Mater 31:597-618. https://doi.org/10. 1021/acs.chemmater.8b04444

Selvaranjan K, Navaratnam S, Rajeev P, Ravintherakumaran N (2021) Environmental challenges induced by extensive use of face masks during COVID-19: a review and potential solutions. Environ Challenges 3:100039. https://doi.org/ 10.1016/j.envc.2021.100039

Shalan AE, Oshikiri T, Narra S et al (2016) Cobalt oxide $\left(\mathrm{CoO}_{\mathrm{x}}\right)$ as an efficient hole-extracting layer for high-performance inverted planar perovskite solar cells. ACS Appl Mater Interfaces 8:33592-33600. https://doi.org/10.1021/acsami. $6 \mathrm{~b} 10803$

Singh N, Goldsmith BR (2020) Role of electrocatalysis in the remediation of water pollutants. ACS Catal 10:3365-3371. https://doi.org/10.1021/acscatal.9b04167

Steffen W, Richardson K, Rockstrom J et al (2015) Planetary boundaries: guiding human development on a changing planet. Science 347:1259855-1259855. https://doi.org/10. 1126/science. 1259855

Tang B, Xu C, Zou F et al (2020) Palladium nanoparticle colored cotton fabric as a highly efficient catalyst for colorimetric sensing of $\mathrm{H}_{2} \mathrm{O}_{2}$. Cellulose 27:7791-7803. https://doi.org/10.1007/s10570-020-03274-8

Thakur V (2021) Framework for PESTEL dimensions of sustainable healthcare waste management: Learnings from COVID-19 outbreak. J Clean Prod 287:125562. https://doi. org/10.1016/j.jclepro.2020.125562

Tian X, Xin B, Lu Z, Gao W, Zhang F (2019) Electrospun sandwich polysulfonamide/polyacrylonitrile/polysulfonamide composite nanofibrous membranes for lithium-ion batteries. RSC Adv 9:11220-11229. https://doi.org/10. 1039/C8RA10229E

Tokoro H, Tarora W, Namai A et al (2018) Direct observation of chemical conversion from $\mathrm{Fe}_{3} \mathrm{O}_{4}$ to $\varepsilon-\mathrm{Fe}_{2} \mathrm{O}_{3}$ by a nanosize wet process. Chem Mater 30:2888-2894. https://doi.org/ 10.1021/acs.chemmater.7b03708

van Straten B, Robertson PD, Oussoren H et al (2021) Can sterilization of disposable face masks be an alternative for imported face masks? a nationwide field study including 19 sterilization departments and 471 imported brand types during COVID-19 shortages. PLoS ONE 16:e0257468. https://doi.org/10.1371/journal.pone.0257468

Wang J-C, Lou H-H, Xu Z-H et al (2018a) Natural sunlight driven highly efficient photocatalysis for simultaneous degradation of rhodamine $\mathrm{B}$ and methyl orange using I/C codoped $\mathrm{TiO}_{2}$ photocatalyst. J Hazard Mater 360:356-363. https://doi.org/10.1016/j.jhazmat.2018.08.008

Wang Q, Wei H, Zhang Z et al (2018b) Nanozyme: an emerging alternative to natural enzyme for biosensing and immunoassay. TrAC Trends Anal Chem 105:218-224. https://doi.org/10.1016/j.trac.2018.05.012

Wei H, Wang E (2013) Nanomaterials with enzyme-like characteristics (nanozymes): next-generation artificial enzymes. Chem Soc Rev 42:6060-6093. https://doi.org/10. 1039/C3CS35486E

Wei Y, Cui M, Ye Z, Guo Q (2020) Environmental challenges from the increasing medical waste since SARS outbreak. J Clean Prod. https://doi.org/10.1016/j.jclepro.2020. 125246

Wibisono Y, Fadila CR, Saiful Saiful MRB (2020) Facile approaches of polymeric face masks reuse and reinforcements for micro-aerosol droplets and viruses filtration: a Review. Polymers 12(11):2516. https://doi.org/10.3390/ polym 12112516

Wu X, Shi Z, Fu S et al (2016) Strategy for synthesizing porous cellulose nanocrystal supported metal nanocatalysts. ACS Sustain Chem Eng 4:5929-5935. https://doi.org/10.1021/ acssuschemeng.6b00551

Xia L, Zhou S, Zhang C et al (2020) Environment-friendly Juncus effusus-based adsorbent with a three-dimensional network structure for highly efficient removal of dyes from wastewater. J Clean Prod 259:120812. https://doi.org/10. 1016/j.jclepro.2020.120812

Xu X, Liu F, Jiang L, Zhu JY, Haagenson D, Wiesenborn DP (2013) Cellulose nanocrystals vs. cellulose nanofibrils: a comparative study on their microstructures and effects as polymer reinforcing agents. ACS Appl Mater Interfaces 5:2999-3009. https://doi.org/10.1021/am302624t

Xu C, Rangaiah GP, Zhao XS (2014) Photocatalytic degradation of methylene blue by titanium dioxide: experimental and modeling study. Ind Eng Chem Res 53:14641-14649. https://doi.org/10.1021/ie502367x 
Yamashita T, Hayes P (2008) Analysis of XPS spectra of $\mathrm{Fe}^{2+}$ and $\mathrm{Fe}^{3+}$ ions in oxide materials. Appl Surf Sci 254:2441-2449. https://doi.org/10.1016/j.apsusc.2007.09. 063

Yan W, Chen C, Wang L, Zhang D, Li AJ, Yao Z, Shi LY (2016) Facile and green synthesis of cellulose nanocrystal-supported gold nanoparticles with superior catalytic activity. Carbohydr Polym 140:66-73. https://doi.org/10.1016/j. carbpol.2015.12.049

Yildirimer L, Thanh NTK, Loizidou M, Seifalian AM (2011) Toxicology and clinical potential of nanoparticles. Nano Today 6:585-607. https://doi.org/10.1016/j.nantod.2011. 10.001

Yonar T, Kestioglu K, Azbar N (2006) Treatability studies on domestic wastewater using $\mathrm{UV} / \mathrm{H}_{2} \mathrm{O}_{2}$ process. Appl Catal B Environ 67:223-228. https://doi.org/10.1016/j.apcatb. 2006.04.022

Zangeneh H, Zinatizadeh AAL, Habibi M, Akia M, Isa MH (2015) Photocatalytic oxidation of organic dyes and pollutants in wastewater using different modified titanium dioxides: a comparative review. J Ind Eng Chem 26:1-36. https://doi.org/10.1016/j.jiec.2014.10.043

Zheng X, Zhang D, Gao Y, Wu Y, Liu Q, Zhu X (2019) Synthesis and characterization of cubic $\mathrm{Ag} / \mathrm{TiO}_{2}$ nanocomposites for the photocatalytic degradation of methyl orange in aqueous solutions. Inorg Chem Commun 110:107589. https://doi.org/10.1016/j.inoche.2019.107589

Zhu Z, Cai H, Sun D-W (2018) Titanium dioxide $\left(\mathrm{TiO}_{2}\right)$ photocatalysis technology for nonthermal inactivation of microorganisms in foods. Trends Food Sci Technol 75:23-35. https://doi.org/10.1016/j.tifs.2018.02.018

Zhu N, Zhang D, Wang W et al (2020) A novel coronavirus from patients with oneumonia in China, 2019. N Engl J Med 382:727-733. https://doi.org/10.1056/nejmoa2001017

Publisher's Note Springer Nature remains neutral with regard to jurisdictional claims in published maps and institutional affiliations. 